\title{
Guidelines for the management of asthma in adults: Evidence and recommendations
}

\author{
Theerasuk Kawamatawong, ${ }_{1}$ Atik Sangasapaviriya, ${ }^{2}$ Narongkorn Saiphoklang, ${ }^{3}$ Nittha Oer-areemitr, ${ }^{4}$ Thitiwat Sriprasart, ${ }^{5}$ \\ Harutai Kamalaporn, ${ }^{6}$ Kumpol Amnuaypattanapon, ${ }^{7}$ Ticha Rerkpattanapipat, ${ }^{8}$ Naricha Chirakalwasan, ${ }^{9}$ \\ Manaphol Kulpraneet, ${ }^{10}$ Chamard Wongsa, ${ }^{11}$ Hiroshi Chantaphakul, ${ }^{12}$ Santi Silairatana, ${ }^{13}$ Orapan Poachanukoon ${ }^{14}$; \\ on behalf of the Thai Asthma Council (TAC)
}

\begin{abstract}
The multidisciplinary experts in Thailand developed an asthma management recommendation that was relevant to low-middle income countries (LMICS). Population level consideration about asthma management is emphasized. The healthcare systems, access to and availability of treatments as well as the asthma populations vary from country to country in LMICS. The feasibility in clinical practice for implementation is also a major issue. For these reasons, the practice guidelines that are relevant to local contexts are essential to improve better asthma control. Furthermore, integrative and collaboration between asthma experts and the public health sector to implement and discriminate such guidelines will help to achieve these challenging goals. The topics covered include the current asthma situation in Thailand and the Asia-Pacific region, the definition of asthma, asthma diagnosis, assessment of asthma patients, asthma treatment - both pharmacological and non-pharmacological, management of asthma exacerbation, management of asthma comorbidities, treatment of asthma in special conditions, severe and uncontrolled asthma, Thai alternative medicine and asthma, and asthma and coronavirus disease-19 (COVID-19).
\end{abstract}

\section{Affiliations:}

Division of Pulmonary and Critical Care Medicine, Ramathibodi Hospital, Mahidol University, Bangkok, Thailand

Allergy and clinical immunology, Department of Medicine, Phramongkutklao College of Medicine, Bangkok, Thailand

3 Division of Pulmonary and Critical Care Medicine, Department of Internal Medicine, Faculty of Medicine, Thammasat University, Pathum Thani, Thailand

4 Department of Pulmonary and Critical Care Medicine, Phramongkutklao Hospital, Bangkok, Thailand

Division of Pulmonary and Critical Care Medicine, Department of Medicine, Faculty of Medicine, Chulalongkorn University and King Chulalongkorn Memorial Hospital, Thai Red Cross Society, Bangkok, Thailand

6 Division of Pediatric Pulmonology, Department of Pediatrics, Faculty of Medicine, Ramathibodi hospital, Mahidol University, Bangkok, Thailand

Department of Emergency Medicine, Faculty of Medicine, Thammasat University, Pathum Thani, Thailand

8 Allergy Immunology and Rheumatology Division, Department of Medicine, Faculty of Medicine, Ramathibodi Hospital, Mahidol University, Bangkok, Thailand

9 Division of Pulmonary and Critical Care Medicine,

Department of Medicine, Faculty of Medicine,

Chulalongkorn University, Bangkok, Thailand and Excellence Center for Sleep Disorders, King Chulalongkorn Memorial Hospital, Thai Red Cross Society, Bangkok, Thailand

${ }^{10}$ Division of Pulmonary and Critical Care, Department of Medicine Srinakarinwirot University, Bangkok, Thailand

${ }^{11}$ Division of Allergy and Clinical Immunology, Department of Medicine, Faculty of Medicine Siriraj Hospital, Mahidol University, Bangkok, Thailand
${ }^{12}$ Division of Allergy and Clinical Immunology, Department of Medicine, Faculty of Medicine, Chulalongkorn University, King Chulalongkorn Memorial Hospital, Thai Red Cross Society, Bangkok, Thailand

${ }^{13}$ Division of Pulmonary Medicine and Pulmonary Critical Care, Department of Medicine, Faculty of Medicine Vajira Hospital, Navamindradhiraj University, Bangkok, Thailand

${ }^{14}$ Center of Excellence for Allergy, Asthma and Pulmonary Diseases, Department of Pediatrics, Thammasat University Hospital, Pathum Thani, Thailand

\section{Corresponding author:}

Theerasuk Kawamatawong

Division of Pulmonary and Critical Care Medicine,

Ramathibodi Hospital, Mahidol University, Bangkok, Thailand

E-mail: ktheerasuk@hotmail.com

\section{The state of asthma in Thailand}

There are currently at least 300 million people who suffer from asthma worldwide, and the prevalence rate has been increasing in Latin America, Europe, Africa, and Asia. In Thailand, the prevalence of asthma in adults is approximately 3\%. ${ }^{1}$ Data from a survey in Thai adult asthma patients found that $17 \%$ had been admitted in the past year, $7 \%$ of whom were admitted to the intensive care unit. The mortality rate of adult asthma patients admitted to tertiary care hospitals was $2.17 \% .^{2}$ Additionally, $35 \%$ of asthma patients had visited the emergency department, and $44 \%$ had been absent from school or work due to an asthma attack. ${ }^{3}$ 
The direct cost for adult Thai asthma patients is 1,032 USD per year, which is equal to $19.14 \%$ of the gross domestic product (GDP) per capita. This is less than the direct and indirect cost for adult asthma patients in the US due to regional differences in treatment costs. ${ }^{4}$ Although up-to-date clinical guidelines for asthma treatment exist, most patients still suffer from inadequate asthma control and their usage of inhaled corticosteroids (ICS) is often limited or irregular. In Thailand, $62 \%$ of asthma patients report good control, but the actual rate according to the GINA guidelines is only $8 \%$, indicating that Thai asthma patients likely underestimate the severity of their condition. ${ }^{5}$ The rate of ICS use in asthma control increased from $6.7 \%$ in 2000 to $57 \%$ in $2011 .{ }^{6}$ However, only $58 \%$ of patients use ICS on a daily basis. This can lead to asthma attacks, which can impact patients' quality of life, work/school attendance, exercise habits, mental health, mood, and social life. ${ }^{3}$

The Thai Clinical Practice Guidelines for Diagnosis and Management of Asthma in Adult Patients were first issued in 1997 and revised in 2004 and 2008 based on the Global Initiative for Asthma (GINA) guidelines with some modifications for their adaptation in Thailand. This 2020 version of the Thai clinical practice guidelines was developed as a short evidence-based summary by multidisciplinary experts involved in the management of asthma in Thailand. These experts include pulmonologists, allergy and immunology physicians, and emergency physicians. The guidelines were developed with the specific aim maximizing their practical effectiveness in Thailand, in which public health resources are limited.

\section{Asthma definition}

Asthma is a disease of airway inflammation resulting in expiratory airflow obstruction from airway smooth muscle contraction. Its clinical course characterized by intermittent attacks, which can be recurrent. Common symptoms of asthma are wheezing respiration, shortness of breath, chest tightness, and cough. These symptoms may vary and depend on asthma duration and severity.

\section{Characteristics of asthma}

Asthma symptoms and airway obstruction depend on disease duration and severity. There are various stimuli that can exacerbate the condition including exercise, allergens, irritants, weather, or viral respiratory tract infection.

Airway obstruction in asthma may improve spontaneously or with bronchodilators. Asthma symptoms vary, and asthma-free periods may last for several weeks or months. However, severe asthma attacks can be fatal. Generally, asthma is related to airway hyperresponsiveness from both direct and indirect stimuli resulting in chronic airway inflammation. Such inflammation is always present in asthma patients regardless of symptoms or lung function.

\section{Clinical characteristics of asthma}

The clinical characteristics of asthma can vary widely depending its causes. Currently, asthma is categorized by population characteristics, clinical features, and pathophysiology. However, there is no evidence of any correlation between pathology and clinical characteristics/response to treatment. Further in-depth research is required to understand these issues. Clinical characteristics of asthma can be categorized into five types as follows and are shown in table 1:

1. Asthma from allergy: This condition can be diagnosed easily, as onset occurs during childhood and the patient often has a family history of allergy such as eczema, allergic rhinitis, or food/drug allergies. Pre-treatment sputum examination will show evidence of eosinophilic inflammation. These patients usually response to ICS.

2. Asthma without allergy: Airway inflammation is caused by neutrophils, eosinophils, or low white blood cell count. These patients usually respond to ICS on a short-term basis.

3. Adult asthma: commonly found in women and not related to allergy. Patients may not respond to ICS or may require a high dosage. Adult asthma may be occupation related.

4. Asthma with permanent airway obstruction: permanent airway obstruction caused by long-term asthma or partially reversible airway obstruction, which results in structural airway changes.

5. Asthma in obesity: found in obese patients who have respiratory symptoms with eosinophilic airway inflammation.

Table 1. Asthma phenotypes, key diagnosis and potential treatments

\begin{tabular}{|c|c|c|}
\hline Asthma phenotypes & Key diagnosis & Potential treatments \\
\hline Asthma from allergy & $\begin{array}{l}\text { The evidence of aller- } \\
\text { gic sensitization (skin } \\
\text { prick test or serum } \\
\text { specific IgE) and } \\
\text { association of asthma } \\
\text { symptoms }\end{array}$ & $\begin{array}{l}\text { ICS containing regi- } \\
\text { mens, immunologic } \\
\text { treatments, anti-IgE } \\
\text { and immunotherapy } \\
\text { Allergen avoidance }\end{array}$ \\
\hline $\begin{array}{l}\text { Asthma without } \\
\text { allergy }\end{array}$ & $\begin{array}{l}\text { Lack of evidence of } \\
\text { allergic sensitization }\end{array}$ & $\begin{array}{l}\text { ICS containing reg- } \\
\text { imens }\end{array}$ \\
\hline Adult asthma & $\begin{array}{l}\text { Late onset or adult-on- } \\
\text { set asthma }\end{array}$ & $\begin{array}{l}\text { ICS containing reg- } \\
\text { imens }\end{array}$ \\
\hline $\begin{array}{l}\text { Asthma with } \\
\text { permanent airway } \\
\text { obstruction }\end{array}$ & $\begin{array}{l}\text { The present of irre- } \\
\text { versible airflow limita- } \\
\text { tion from spirometry } \\
\text { either FEV } / F V C \text { ratio } \\
\text { or absence of broncho- } \\
\text { dilator reversibility }\end{array}$ & $\begin{array}{l}\text { ICS, LAMA, bronchial } \\
\text { thermoplasty }\end{array}$ \\
\hline Asthma in obesity & The increased BMI & ICS, weight reduction \\
\hline
\end{tabular}

Abbreviations: ICS; inhaled corticosteroids, IgE; immunoglobulin E, LAMA; long-acting antimuscarinics, $\mathrm{FEV}_{1}$; forced expiratory volume in 1 second, FVC; forced vital capacity 


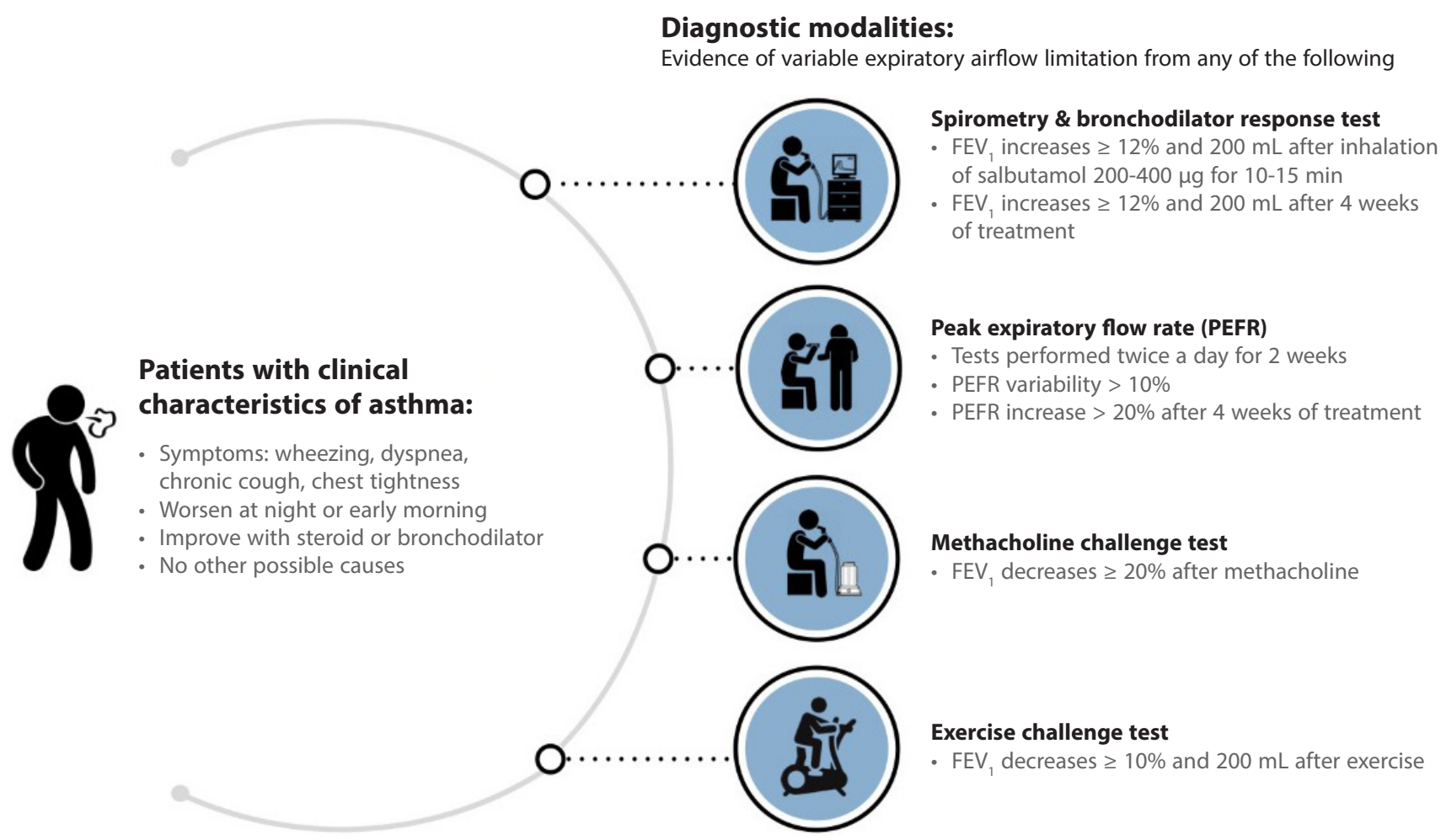

Figure 1. Diagnosis of asthma is based on history of typical asthma characteristics and evidence of expiratory airflow limitation.

\section{Diagnosis of asthma}

Diagnosis of asthma is based on the following two items:

1. Asthma symptoms: wheezing, dyspnea, cough, or chest tightness. These symptoms worsen during the night or early morning. Severity of symptoms varies overtime and worsen by precipitating factors include infection such as common cold, allergens, irritants such exposure to air pollution and tobacco smoke, medications, primarily the non-steroidal anti-inflammatory agents (NSAIDS) and beta-blockers and non-specific manner such as exercise and hyperventilation. ${ }^{7-9}$

Note there should be no other possible causes of these symptoms, and they should improve with ICS or bronchodilator treatment.

2. Evidence of variable expiratory airflow limitation based on a pulmonary function test (Figure 1).

\section{Pulmonary function test}

A pulmonary function test is performed to ascertain evidence of variable expiratory airflow limitation. The following three types of pulmonary function test can be used (criteria for variable expiratory airflow limitation are also provided):

\section{Spirometry}

1.1 evidence of airway obstruction with severity assessment: $\mathrm{FEV}_{1} / \mathrm{FVC}$ less than 0.75-0.80.

1.2 bronchodilator reversibility: $\mathrm{FEV}_{1}$ increases by 200 $\mathrm{ml}$ and $12 \%$ or over from baseline. This test can be performed before or after treatment. The pretreatment test is performed after 15 minutes of inhalation of a short-acting bronchodilator such as salbutamol (200-400 micrograms), while the post-treatment test is performed using controller medication over a period of 4 weeks. ${ }^{10}$

\section{Peak expiratory flow $(P E F)^{11,12}$}

2.1 An increase in PEF of greater than $60 \mathrm{~L} / \mathrm{min}$ or $20 \%$ after inhalation of a short-acting bronchodilator. Note that PEF has less validity than spirometry.

2.2 PEF variability: measurement of PEF twice a day for 1-2 weeks without any treatment.

2.3 An increase in PEF greater than $20 \%$ after 4 weeks of treatment with an asthma controller.

3. Airway hyperresponsiveness (AHR)

In patients with a history and physical examination compatible with asthma but normal spirometry, the methacholine challenge test may be performed. The diagnostic criterion is a required methacholine concentration of less than $4 \mathrm{mg} / \mathrm{mL}\left(\mathrm{PC}_{20}\right) .{ }^{13}$ This test should be performed in specialized health care facilities. 


\section{Assessment of Asthma Patients}

Evolution of asthma assessment

Various sets of asthma guidelines have been developed and revised over the past several decades. The first international guidelines were developed at the GINA workshop in 1993 as a result of a collaboration between the National Heart Lung and Blood Institute, US National Institute of Health (NIH), and World Health Organization (WHO) and were first published in 1995. There are currently several other sets of guidelines in use including the Expert Panel Report (EPR) by the US National Asthma Education and Prevention Program Coordinating Committee, the British Thoracic Society Guidelines (BTS), the Canadian Asthma Guidelines by the Canadian Thoracic Society, and the 2019 Thai Asthma Guideline in Adults by the Thai Asthma Council (TAC). ${ }^{14-17}$ All current guidelines focus on asthma control assessment rather than asthma severity assessment. This was not always the case. The 1995 GINA guidelines, for example, categorized asthma by severity, and in 2006, they assessed asthma severity by frequency of daytime asthma symptoms, frequency of nighttime asthma symptoms, and $\mathrm{FEV}_{1}$ or PEFR and then divided severity of asthma into four categories as follows:

Level 1: Intermittent asthma

Level 2: Mild persistent asthma

Level 3: Moderate persistent asthma

Level 4: Severe persistent asthma

Treatments were to be provided based on the severity of asthma. However, subsequent evidence has shown that symptoms of asthma are not related to $\mathrm{FEV}_{1}$. Thus, in 2003, GINA changed its categorization of asthma to be based on control level. In the 2006 guidelines, asthma was categorized into three groups by control level plus future risk factors (based on daytime symptoms, nighttime symptoms, reliever use, $\mathrm{FEV}_{1}$ or PEFR, and history of an asthma attack in the past year), as follows:

1. Controlled asthma

2. Partly controlled asthma

3. Uncontrolled asthma

However, the Thai Asthma Council (TAC) recommends classification into two broad categories according to level of control, i.e., uncontrolled asthma and well controlled asthma, as show in Figure 2.

Asthma control is defined by the patient's clinical characteristics that are improved by treatment and consists of two components:

1. Current asthma control - evaluated by symptoms and limitations to physical activity that impact quality of life.

2. Risk of future adverse events - includes loss of asthma control, asthma exacerbation, accelerated decline in lung function, and treatment side effects.

Asthma management is aimed at achieving asthma control as assessed by the components listed above. Current symptom control is focused on the past 4 weeks, and future risk is particularly concerned with asthma exacerbation, as shown in Figure 2.

\section{Asthma Management Goal}

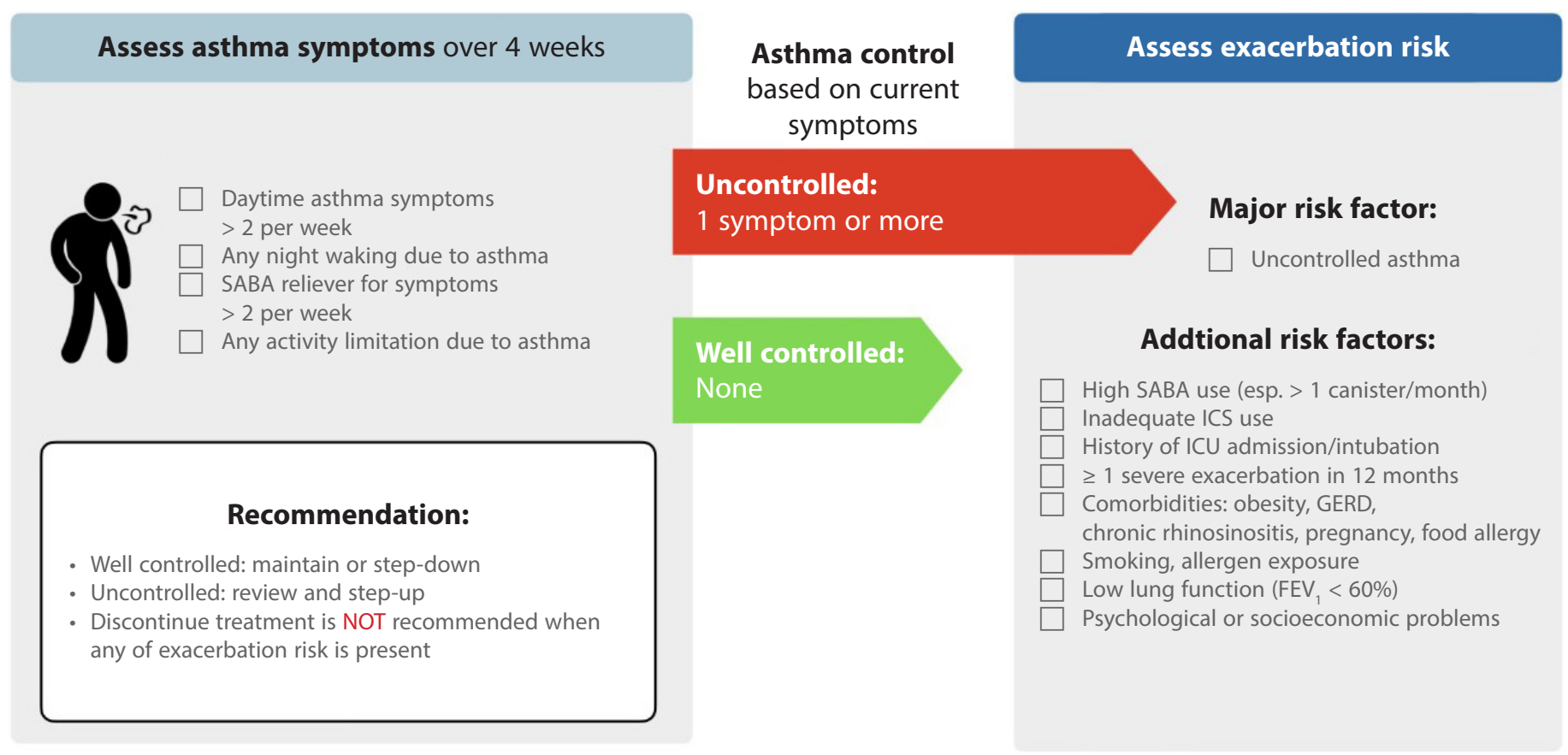

Figure 2. Asthma management goals and asthma control. Assessment of asthma control consists of examining asthma symptoms and exacerbation risk. 
Asthma severity is an indicator of asthma control after external factors are excluded such as misdiagnosis, poor medication compliance, incorrect inhalation technique, and comorbid diseases. Asthma severity indicates the intensity of treatment required to control asthma and underlying disease activity. Severe asthma is defined by a need for a high-intensity treatment to control asthma at all times or uncontrolled asthma even with high-intensity treatment. Asthma treatment depends on severity in treatment-naïve patients or control in treatment-experienced patients. ${ }^{18}$

Factors used to assess asthma severity may be similar to those used to assess control such as symptoms, pulmonary function tests, asthma exacerbation, or asthma treatments. It can often be difficult for clinicians to assess asthma severity or control based on clinical manifestations or responsiveness to treatment. In other words, asthma control may be assessed based on asthma severity or whether symptoms improve/resolve with treatment. From a research perspective, the outcomes of asthma treatment may include not only asthma symptoms but also pulmonary function tests, quality of life, inflammatory biomarkers, or healthcare utilization such as asthma exacerbation or unscheduled visits. ${ }^{12,19-21}$

In clinical practice, assessment for asthma control may be easier than assessment for asthma severity, as asthma severity is dynamic and may be affected by treatment. In addition, most asthma patients have likely received prior treatment, and previous ICS or ICS/LABA use may affect asthma control status. ${ }^{22,23}$ This means that physicians must review previous treatments before determining patients' level of control. The Thai Asthma Council (TAC) recommends the three-pronged AAR approach to asthma control listed below and shown in Figure 3.
A: assess asthma: assess diagnosis, symptoms, risk factors, and inhaled medications.

A: adjust treatment: adjust medication treatment, non-pharmacological treatment, treatment of other asthma-precipitating factors, and the patient's lifestyle.

R: review response: a review of treatment response, pulmonary function, and side effects from treatment.

Most asthma patients underestimate their asthma severity and overestimate their control status. A previous study from nine Asia-Pacific countries, including Australia, China, Hong Kong, India, Malaysia, Singapore, South Korea, Taiwan, and Thailand, found that only $8 \%$ of Thai asthma patients had been able to control their asthma symptoms over the previous 4 weeks. $^{5}$ In addition, only about one-third of Thai asthma patients who reported good asthma control had had actually achieved good control as defined by the GINA guidelines. ${ }^{3}$

Overall asthma control consists of symptom control and reduction of future risk. ${ }^{23}$ The 2020 GINA strategy categorizes current clinical control of asthma into three levels (well controlled, partly controlled, and uncontrolled) and future risk of poor asthma outcomes into three categories (risk factors of exacerbation, risk of fixed airflow obstruction, and risk of medication side effects), as show in Figure 2. ${ }^{7}$ The Thai Asthma Council (TAC) recommends a more simplified classification of asthma symptoms as either well controlled or uncontrolled, placing the greatest importance on uncontrolled symptoms as they carry a risk of asthma exacerbation.
- Treatment for asthma control
- Nonpharmacologic treatment
- Asthma education \& counselling

\section{Asthma Management Process}

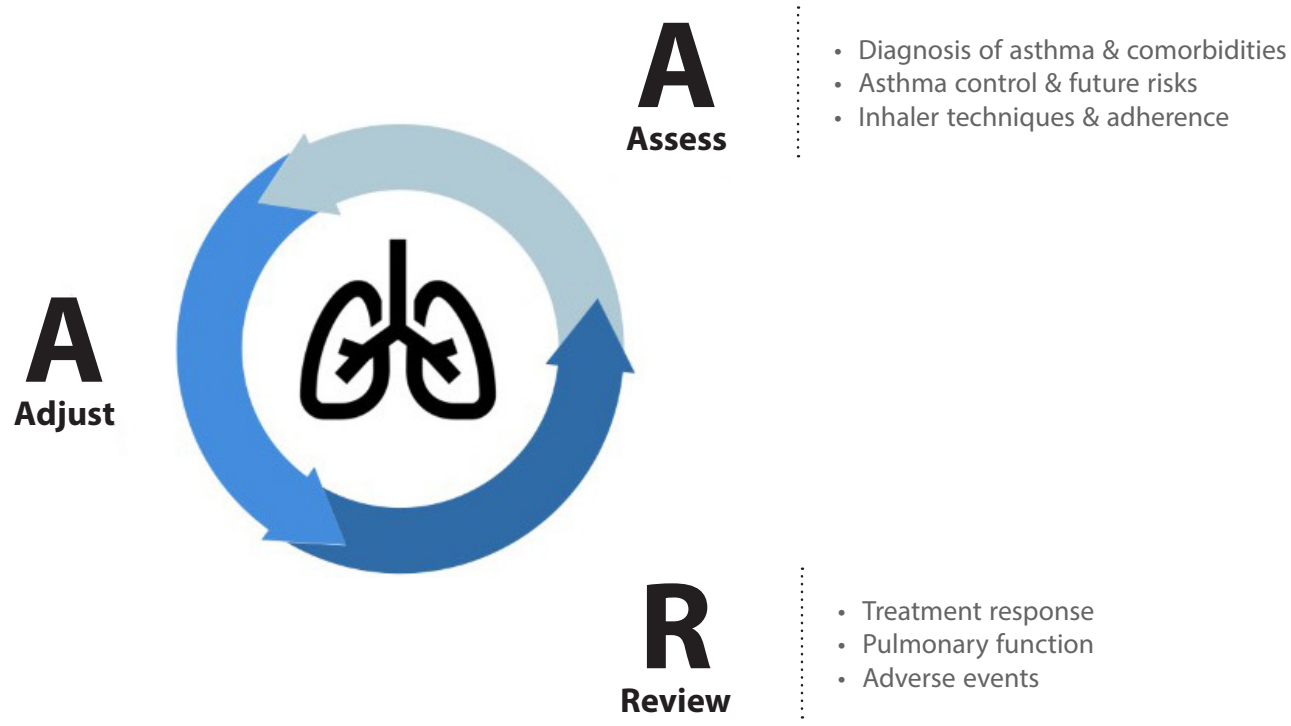

Figure 3. The three dimensions of asthma management based on the Thai Asthma Council (TAC)'s AAR method. A: Assess the diagnosis of asthma and comorbidities, asthma control, and inhaler technique and adherence; A: Adjust both pharmacologic and non-pharmacologic treatment including asthma education and counseling; R: Review treatment response and adverse events including pulmonary function. 
Table 2. Comparison between the Asthma Control Test (ACT) and Asthma Control Questionnaire-7 (ACQ-7) as composite scores for assessing asthma control in clinical practice

\begin{tabular}{|c|c|c|}
\hline Factors & ACT & ACQ-7 \\
\hline Duration of assessment & 4 weeks & 1 week \\
\hline Score & 5-point scale (total of 5-25) & 7-point scale (total of 0-6) \\
\hline Interpretation & $\begin{array}{c}\mathrm{ACT} \geq 20 \\
\text { (well-controlled asthma) } \\
16 \leq \mathrm{ACT} \leq 19 \\
\text { (partly controlled asthma) } \\
\mathrm{ACT} \leq 15 \\
\text { (poorly controlled asthma) }\end{array}$ & $\begin{array}{c}\mathrm{ACQ} \leq 0.75 \\
\text { (well-controlled asthma) } \\
\mathrm{ACQ} \geq 1.5 \\
\text { (not well-controlled asthma) }\end{array}$ \\
\hline Items & 5 items & ACQ-5 (5 items), ACQ-7 (7 items) \\
\hline Limits daily activities & $\checkmark$ & $\checkmark$ \\
\hline Shortness of breath & $\checkmark$ & $\checkmark$ \\
\hline Disrupts sleep & $\checkmark$ & $\checkmark$ \\
\hline SABA use & $\checkmark$ & $\checkmark$ \\
\hline Effect of global control & $\checkmark$ & $\checkmark$ \\
\hline Frequency of wheeze & - & $\checkmark$ \\
\hline pre-bronchodilator $\mathrm{FEV}_{1}$ & - & $\checkmark$ \\
\hline
\end{tabular}

Abbreviations: SABA; short-acting $\beta 2$ agonists; $\mathrm{FEV}_{1}$ : forced expiratory volume in 1 second.

Objective asthma assessment using a questionnaire is simple and practical. There have been several questionnaires developed to assess asthma control or quality of life such as:

1. The Composite Scores of Asthma Control, i.e., the Asthma Control Test (ACT score), Asthma Control Questionnaire (ACQ), and Asthma Therapy Assessment Questionnaire (ATAQ). The total numeric score is the summation of all question scores, as shown in Table 2.

2. The Asthma-Related Quality of Life Questionnaire, i.e., the Mini Asthma-Related Quality of Life Questionnaire (mini-AQLQ)

\section{Type 2 asthma biomarkers for asthma control}

In the past decades, biomarkers have been used to assess asthma control, particularly those measured using noninvasive techniques. Biomarkers can be detected based on respiratory factors such as induced sputum cell counts and fractional concentration of exhaled nitric oxide (FeNO) or from blood tests that measure serum eosinophils or serum periostin. ${ }^{24,25}$

The FeNO test is widely used and is considered the standard method of asthma biomarker detection. However, a previous study in Thai asthma patients found that exhaled FeNO was not related to asthma control based on ACT score. ${ }^{26}$ At present, type 2 inflammatory biomarkers are used to determine asthma phenotype in severe cases using precision medication in order to select targeted treatments.

\section{Asthma treatment}

\section{Pharmacological treatment of asthma}

One aim of asthma treatment is asthma control, which is defined as current symptom control (no asthma symptoms either during the day or at night, no short-acting bronchodilator use, no asthma exacerbation, ability to engage in normal daily activities including exercise, and normal pulmonary function) and prevention of future risk (asthma exacerbation, deaths from asthma, the decline of pulmonary function resulting in airway remodeling, and side effects from treatment). The principles of asthma treatment are as follows:

- A new asthmatic patient should be treated according to asthma severity (Figure 4)

- All asthmatic patients should have regular asthma control medication and reliever medication as needed.

- Inhaled corticosteroids (ICS) are a mainstay treatment to control asthma. The patient should start with a low dose, which can be adjusted based on severity (Figure 4).

- If low-dose inhaled corticosteroid treatment is not ineffective, the dosage can be increased (high dose) or other medications can be used such as long-acting $\beta 2$-agonists, LABA, or leukotriene receptor antagonists (LTRA). An inhaled ICS/LABA in the same device is recommended as it has the highest efficacy. LTRA is an alternative treatment.

- ICS/LABA with formoterol formula is a rapid-acting LABA which can be used as controller and reliever in the same device (maintenance and reliever therapy). 


\section{Recommendations for Initial Treatment}

Severity/frequency of symptoms

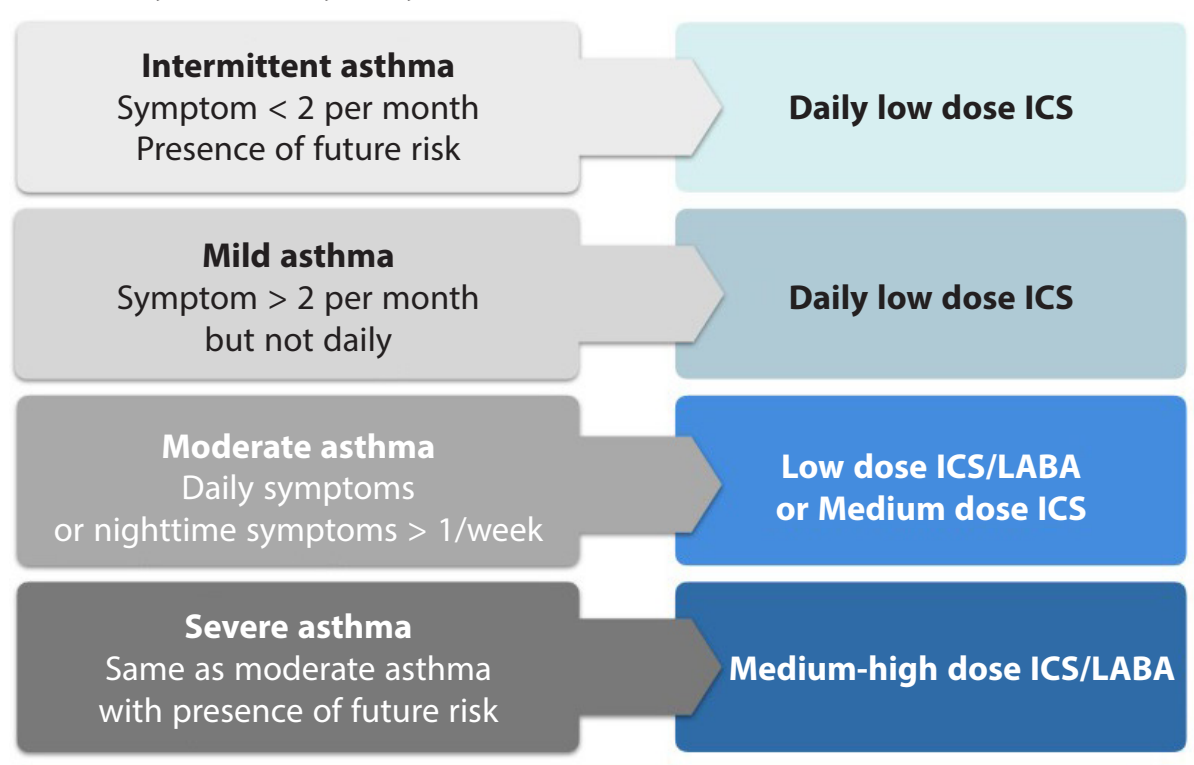

Short-acting bronchodilator provided as reliever in all patients

\section{ICS dosage $(\mu \mathrm{g} / \mathrm{day})$}

\section{Low dose}

Beclomethasone dipropionate 200-500

Budesonide 200-400

- Fluticasone propionate $100-250$

Fluticasone furoate 100

\section{Medium dose}

Beclomethasone dipropionate 500-1000

- Budesonide 400-800

- Fluticasone propionate $250-500$

- Fluticasone furoate 200

Figure 4. Initial treatment options for newly-diagnosed asthmatic patients. The recommendation of initial treatment is based on the severity and/or frequency of symptoms

Abbreviations: ICS: inhaled corticosteroid; LABA: long-acting $\beta 2$ agonists

\section{Adjustment for previously treated patients}

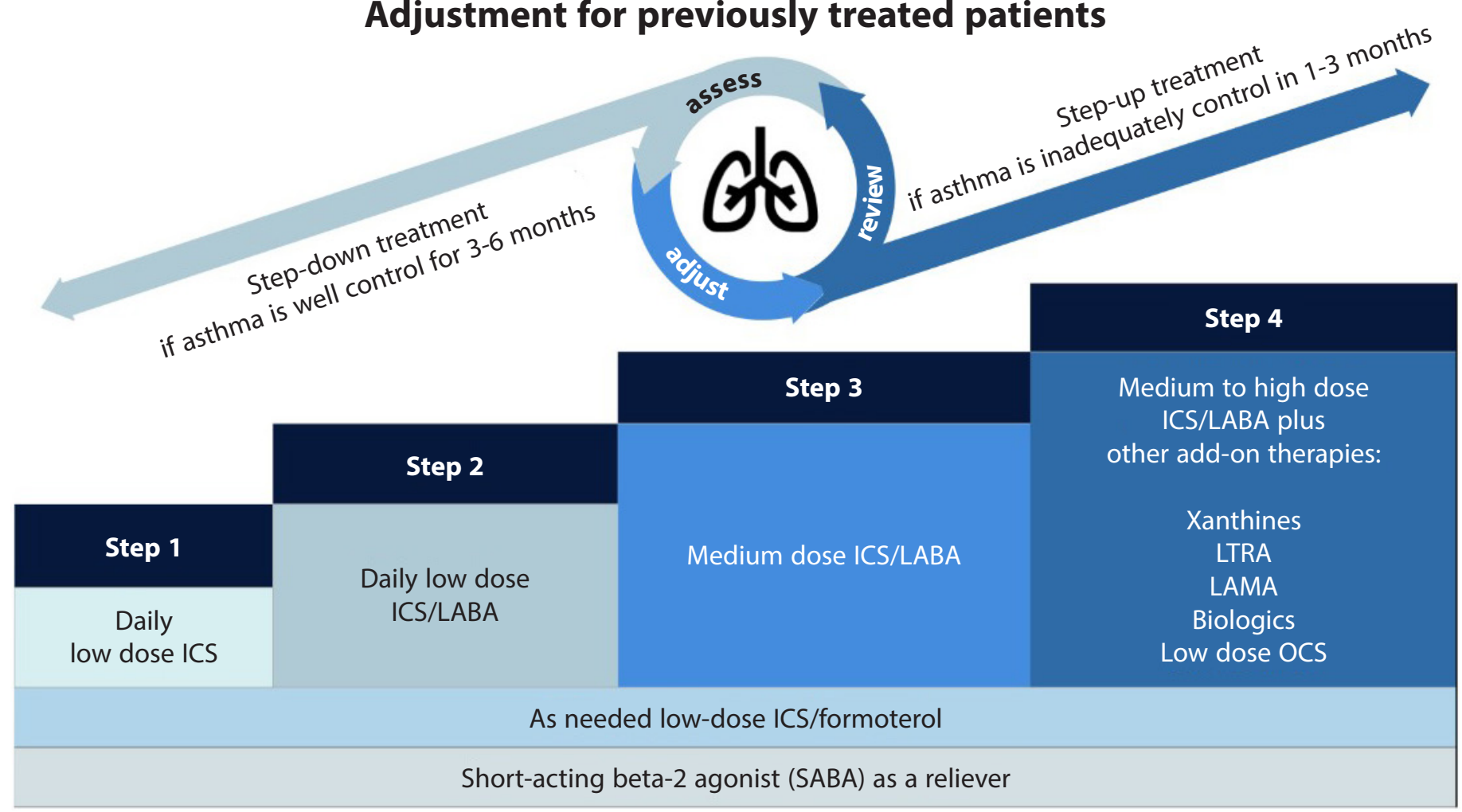

Figure 5. Stepwise treatment of asthma. The step-up and step-down treatment recommendations in previously treated asthmatic patients should be based on the level of asthma control.

Abbreviations: ICS: inhaled corticosteroid; LABA: long-acting $\beta 2$ agonists; SABA: SABA: short-acting $\beta 2$ agonists; LTRA: leukotriene receptor antagonist; LAMA: long-acting muscarinic antagonist; OCS: oral corticosteroid 
- Dosage of controllers and relievers in previously treated asthma patients should be increased at 1-3 months if asthma remains inadequately controlled. Step-down therapy can be initiated after 3-6 months of well asthma control, as shown in Figure 5.

- In patients with severe, uncontrolled asthma despite taking a high dosage of ICS/LABA, referral to an asthma specialist is recommended. Additional medications, such as sustained-release xanthine, LTRA, long-acting muscarinic antagonists (LAMA): tiotropium bromide, low-dose prednisolone, or biologic agents (omalizumab, mepolizumab, benralizumab, and dupilumab) may be prescribed, but referral to a specialists should still be considered, as treatment depends on asthma phenotype.

Additional factors associated with uncontrolled asthma should be explored including misdiagnosis, improper technique in using the medication device, poor compliance, surveillance and treatment of comorbid diseases, and allergen avoidance including that of irritants and smoking.

Choice of medication can be made based on pharmacology, efficacy, safety, patient satisfaction, and price. However, factors associated with uncontrolled asthma should be evaluated prior to medication adjustment, as mentioned above. For those who have received prior treatment, medication adjustment can be performed as shown in Figure 5. During each step, short acting bronchodilator as a reliever as needed or low dose ICS/formoterol for dyspnea should be considered.

\section{Step 1 Controller}

For patients with controlled asthma, an inhaled short-acting bronchodilator as needed or low-dose ICS/formoterol can be used. ${ }^{27,28}$ Daily low-dose inhaled corticosteroids should be considered. In asymptomatic or mild asthma with risk factors for asthma exacerbation, intermittent ICS/formoterol may be used in conjunction with alternative treatment with LTRA. ${ }^{29-34}$

\section{Step 2 Controller}

For uncontrolled asthma (based on asthma assessment or presence of risk factors for asthma exacerbation), low-dose inhaled corticosteroids combined with LABA is recommended.

\section{Step 3 Controller}

In cases in which asthma remains uncontrolled after Step 2, medium-dose ICS/LABA combined with an inhaled short-acting bronchodilator as needed or ICS/formoterol is recommended. $22,35-40$

\section{Step 4 Controller}

In cases in which asthma remains uncontrolled after Step 3 resulting in daily daytime and nighttime asthma with decreasing pulmonary function, medium- to high-dose ICS/ LABA can be combined with other medications, such as sustained-release xanthine, LTRA, long-acting muscarinic antagonists (LAMA; tiotropium bromide), low-dose prednisolone
( $\leq 7.5 \mathrm{mg}$ prednisolone/day), or biologic agents (omalizumab, mepolizumab, or benralizumab). Referral to an asthma specialist is also required.

\section{Non-pharmacological Therapies \\ Smoking cessation}

Smoking, vaping, and exposure to second-hand smoke can cause severe and uncontrolled asthma. Several studies have shown that individuals who are exposed to cigarette or electronic cigarette smoke have an increased risk of asthma. Asthma patients who are current smokers should be encouraged to quit smoking as soon as possible. ${ }^{41-43}$ At every visit, smokers should be given smoking cessation treatment.

\section{Exercise}

There is evidence that exercise can improve asthma control, increase maximum exercise ability, increase endurance, improve pulmonary function, reduce dyspnea symptoms, improve quality of life, and reduce dependence on healthcare services by reducing asthma exacerbation, antibiotic use, oral corticosteroid use, and emergency room visits. ${ }^{44-46}$ Recommended exercises include swimming, running, biking, or Tai Chi. Patients with severe, uncontrolled asthma should engage in an appropriate exercise 5-7 times/week for 20-30 minutes/ time, for at least 6-8 weeks.

\section{Breathing training}

Breathing training can reduce the patient's respiratory rate, reduce breathing volume, increase abdominal and lateral chest muscle use, encourage nasal breathing, and provide relaxation. In addition, studies have found that breathing training can reduce dyspnea symptoms, improve quality of life, and reduce emotional stress. ${ }^{47,48}$ Such training is thus recommended for asthma patients with symptoms of dyspnea or poor quality of life.

\section{Environmental control}

Control of the home and workplace environment, such as ensuring good ventilation, avoidance of carpet, insecticides, incense, and dust mites, cleaning of bed linen, and restriction of indoor pets, is recommended to reduce asthma stimuli. History taking with regard to workplace details and occupation is necessary in patients with adult-onset asthma. Avoidance of occupational causes of asthma, NSAIDs, and beta-blockers is crucial in these patients. ${ }^{49-51}$

\section{Weight reduction}

Weight reduction by more than $10 \%$ of baseline is recommended, as it can improve both asthma control and pulmonary function. ${ }^{52}$

\section{Vaccination}

Influenza vaccination is recommended annually in asthma patients. The 13 serotype pneumococcal vaccine may be considered in these individuals due to no obvious benefits. ${ }^{53,54}$ 


\section{Bronchial thermoplasty}

Bronchial thermoplasty reduces airway remodeling inhibiting fibroblast and is recommended in patients with uncontrolled asthma or frequent asthma attacks despite having undergone level 5 treatment. Bronchial thermoplasty can reduce the risk of acute asthma attack by $31.4-46.2 \%$, reduce oral corticosteroid use and emergency room visits by $46.0-53.6 \%$, and improve quality of life. ${ }^{51-59}$ The beneficial effects of bronchial thermoplasty may last for 3-5 years. Studies from Thailand have found bronchial thermoplasty to reduce the risk of asthma attack by $50 \%$, which is comparable with the findings of previous studies conducted in Western countries. Oral cortocosteroids and risk of asthma attack are also significantly reduced. Bronchial thermoplasty improves quality of life. Previous studies have found that all patients previously treated with anti-IgE therapy have been able to discontinue the treatment after receiving bronchial thermoplasty.

\section{Asthma patient education ${ }^{60-62}$}

Asthma patients should be educated in the following areas as shown in table 3 .

\section{Table 3. The key information for asthma patient education}

1. General asthma knowledge: causes, symptoms, diagnosis, and clinical course.

2. Principles of asthma treatments - both pharmacological and non-pharmacological.

3. Reliever and control medications: types of medications and their side effects.

4. The importance of regular hospital visits and good medication compliance according to their treatment plan whether or not they are experiencing symptoms.

5. Self-monitoring of exacerbation warning signs and symptoms that require medical attention.

6. Initial treatment in the event of an asthma attack according the patient's individual asthma action plan.

7. Correct inhaler device usage.

8. Common treatment goals between healthcare providers and patients/ caregivers. Physicians should assess and plan based on patient treatment expectations and concerns.

9. Treatment and behavior modifications aimed at improving comorbid diseases such as allergic rhinitis.

10. Avoidance of allergens, smoke, air pollution (e.g., mask wearing), and avoidance of outdoor activities when air quality is poor.

11. Non-competitive exercise that does not cause asthma attacks such as biking, swimming, or Yoga.

12. Avoiding close contact with persons who have respiratory tract infections. Regular annual influenza vaccination is encouraged.

\section{Asthma Action Plan}

The WHO and GINA strategies recommend a written asthma action plan (WAPP) and use of a peak flow meter in asthma patients who are on daily medication. In 2015, an Asthma Care application was developed for use with Thai asthma patients to help patients and healthcare providers develop common goals. ${ }^{62} \mathrm{~A}$ WAPP is a helpful tool that has been shown to significantly reduce hospitalization and absence from school in children with asthma. ${ }^{63}$

\section{Advantages of the Asthma Action Plan ${ }^{63}$}

1. Daily reminder of medications.

2. Indications of airway obstruction before chest discomfort or breathlessness occurs.

3. Treatment during an asthma exacerbation. Asthma patients can assess themselves during asthma exacerbation and choose the appropriate medications at the correct doses without a hospital visit.

4. A media among physicians, patients, and caregivers at home, work, or school.

5. Patients are be made aware of their symptoms and appropriate activities.

\section{Advice on inhaling devices ${ }^{64-66}$}

1. Use of the appropriate inhaling device provides better medication administration, which improves asthma control.

2. The choice of inhaling device should be individualized based on simplicity, inhalation force, price, and efficacy of medication delivery.

3. Considerations regarding individual inhaling devices are as follows:

3.1 A pressurized metered dose inhaler ( $\mathrm{pMDI}$ ) requires push-inhalation skill. A spacer can be used to improve medication administration in cases of poor push-inhalation skill if used with other inhaling devices.

3.2 Dry powder inhaler (DPI) technique varies by device (Turbuhaler $^{\mathrm{TM}}$, Accuhaler ${ }^{\mathrm{TM}}$, Ellipta ${ }^{\mathrm{Tm}}$, Breezhaler ${ }^{\mathrm{TM}}$, or Handihaler $\left.{ }^{\mathrm{rm}}\right)$. Physicians should determine whether the patient is able to use the device correctly. Currently, there are videos available to educate patients in the usage of these devices.

3.3 Peak inspiratory flow rate of less than $30 \mathrm{~L} / \mathrm{min}$ is contraindicated for DPI device use.

4. Physicians should avoid prescribing multiple inhaling devices to one patient to avoid confusion regarding proper use.

5. Physicians should intermittently confirm that the patient is using the device correctly. 


\section{Management of asthma exacerbation}

Acute asthma exacerbation constitutes a severe asthma attack. These patients must undergo asthma severity evaluation along with prompt treatment after diagnosis. Additionally, close monitoring and systematic evaluation of treatment outcomes are necessary and should serve as the basis for emergency room discharge or hospital admission. Proper management of acute asthma exacerbation can reduce relapse rate, hospitalizations, and mortality.

\section{Evaluation}

Asthma patients with acute asthma exacerbation presenting at the emergency room must first be evaluated to determine severity (Table 4). This is particularly important in those patients who require resuscitation or intubation due to drowsiness, cyanosis, or air hunger. Following this, history should be taken regarding risk factors, and physical examination should be performed to determine the proper treatment plan.

Table 4. Severity evaluation by physical examination and initial investigation in acute asthma exacerbation

\begin{tabular}{|c|c|c|}
\hline Evaluation & Mild to moderate & Severe \\
\hline Consciousness & Good & $\begin{array}{l}\text { Agitated, confused, } \\
\text { drowsy, or comatose }\end{array}$ \\
\hline Speech ability & Full sentences & $\begin{array}{l}\text { Unable to speak in full } \\
\text { sentences }\end{array}$ \\
\hline Pulse rate, bpm & $100-120$ & $>120$ \\
\hline Respiration, (/min) & $\leq 30$ & $>30$ \\
\hline Accessory muscle use & No & Yes \\
\hline $\begin{array}{l}\text { Oxygen saturation } \\
\text { (room air) }\end{array}$ & $90-95 \%$ & $<90 \%$ \\
\hline $\begin{array}{l}\text { Peak Expiratory Flow } \\
(\mathrm{PEF})\end{array}$ & $\begin{array}{l}>50 \% \text { (predicted or } \\
\text { best) }\end{array}$ & $\begin{array}{l}\leq 50 \% \text { (predicted or } \\
\text { best) }\end{array}$ \\
\hline
\end{tabular}

Risk factors for acute asthma exacerbation that may lead to a severe condition or death include history of acute asthma exacerbation that required intubation and respirator, history of emergency room visit and having required hospitalization within the past year, current or recent use of oral corticosteroids, use of more than one inhaler/month of a short-acting bronchodilator, presence of psychological symptoms or psychosocial problems, use of hypnotics, non-compliance with treatment/incorporation to treatment, or history of food allergy. ${ }^{67-69}$

\section{Oxygen therapy}

Supplementary oxygen therapy is needed if finger oxygen saturation $\left(\mathrm{SpO}_{2}\right)$ is $93 \%$ or lower. Oxygen saturation should be continuously monitored and kept at over 93\%. ${ }^{69-71}$

\section{Inhaled short-acting $\beta 2$-agonists (SABAs)}

SABAs should be given to all patients with acute asthma exacerbation. Response to this treatment should occur after 15-20 minutes and can be used as an indicator for repeated/continuous SABA administration, hospital admission, or emergency room discharge. Guidelines for SABA administration are as follows:

- In mild to moderate cases, SABAs, such as salbutamol (2.5-5 $\mathrm{mg})$ by nebulization or salbutamol (4001,000 micrograms; 4-10 puffs) via pMDI with a spacer, should be administered. Evaluation for response should be performed at 15-20 minutes after treatment. If there is no clinical improvement or only slight improvement not meeting the discharge criteria, SABAs can be administered every 20 minutes during the first hour of treatment for a total of 3 doses. ${ }^{70,71}$

- In severe cases, a combination of a SABAs and short-acting anticholinergics or antimuscarinics (SAMAs) should be given. This treatment can more effectively reduce the risk of hospital admission and improve pulmonary function than SABAs alone. ${ }^{72,73}$

\section{Systemic corticosteroids}

Systemic corticosteroids should be given in all asthma patients with severe acute asthma exacerbation or risk factors for severe acute asthma exacerbation (Figure 2). The first dose of an inhaled bronchodilator should be administered immediately and corticosteroid treatment should continue until emergency room discharge. Intravenous systemic corticosteroids, such as dexamethasone (4-5 mg) or hydrocortisone (100 mg), can be administered every 6-8 hours. In mild cases, oral prednisolone (30-50 mg/day or $0.5-1 \mathrm{mg} / \mathrm{kg} /$ day) is justified. All patients who receive systemic corticosteroids at the emergency room should be given oral prednisolone to take for 5-7 days after hospital or emergency room discharge. Time to systemic corticosteroid treatment at the emergency room and continuation of treatment after discharge are significantly related with reduction of hospital admission and acute asthma exacerbation relapse. ${ }^{74-77}$

\section{Inhaled corticosteroids}

Inhaled corticosteroids can be administered to patients who have not undergone previous treatment with systemic corticosteroids. A high dose of inhaled corticosteroids within the first hour of an emergency room visit is justified and can reduce hospital admission after discharge as well as reduce the risk of severe acute asthma exacerbation. ${ }^{78,79}$ These medications can be administered in the emergency room if the patient has no history previous use. For those who have previously used inhaled corticosteroids, the dosage should be increased. 


\section{Treatment evaluation}

All patients should be evaluated and monitored continuously for consciousness, vital signs, and $\mathrm{SpO}_{2}$. If patients are drowsy, have unstable vital signs, and/or experience a reduction in $\mathrm{SpO}_{2}$, appropriate treatment should be promptly administered. For mild conditions, inhaled SABAs with a spacer or nebulizer should be given, and continuous systematic evaluation should be performed. Peak expiratory flow (PEF; $\%$ predicted or $\%$ personal best) is the best and most precise indicator for treatment response. PEF should be measured before the first dose of SABA treatment and 15-20 minutes after treatment. These PEF values are indicators of the need for future/continuous SABA treatment or emergency room discharge. If PEF and clinical symptoms improve, emergency room discharge is justified. ${ }^{80,81} \mathrm{~A}$ follow-up appointment at the outpatient department is required for continuous care after an emergency room visit.

\section{Additional medications and treatments}

Antibiotics should be considered only in patients with evidence of bacterial infection such as high-grade fever, green sputum, or pneumonia. Use of cough suppressants or medications that cause dry sputum should be avoided. Central nervous system suppressants and hypnotics should also not be used, as this can result in respiratory suppression. Intravenous or nebulized magnesium sulfate can be considered severe cases that do not fully respond to treatment. ${ }^{82,83}$ Intravenous aminophylline is not recommended. ${ }^{84}$ Noninvasive ventilation or NIV is also not recommended in patients suffering from acute asthma exacerbation at the emergency room due to indications for such treatment being unclear and it providing no benefit in terms of intubation rate reduction. ${ }^{85}$

\section{Management of asthma comorbidities}

Respiratory and non-respiratory diseases/disorders are known to be associated with asthma and may affect asthma control. Common diseases/disorders include chronic rhinitis or chronic sinusitis, gastroesophageal reflux disease, obesity, obstructive sleep apnea, and depression and anxiety disorders.

\section{Chronic rhinitis or chronic sinusitis and asthma}

Asthma and rhinosinusitis have related pathogeneses. Comorbid chronic rhinosinusitis is associated with poor asthma control and increases in CRS symptoms, which negatively affect outcomes. A previous study aimed at characterizing patients with severe asthma showed that $54 \%$ of severe patients had a history of rhinosinusitis versus 33 to $37 \%$ of those with non-severe asthma. In addition, multiple studies have shown that treatment of chronic rhinosinusitis can improve asthma symptoms. ${ }^{86}$

There is strong epidemiologic, pathophysiologic, and clinical evidence elucidating an holistic picture of rhinitis and asthma. Hence, the concept of united airway disease (UAD) has been purposed for a decade. Interactions between the lower and the upper airways are well known and have been extensively studied. Two major UAD phenotypes are allergic (atopic or extrinsic) and nonallergic (nonatopic or intrinsic) UAD ${ }^{87}$
The global prevalence of UAD in terms of allergic rhinitis coexisting asthma varied from region to region. ${ }^{88}$ Epidemiological study has shown that $80 \%$ of asthmatics have coexisting rhinitis, and $30 \%$ of rhinitis patients have asthma.

The differences in prevalence of allergic diseases are underlying by several factor such as infection exposure, the immunization, and life-style factors. In Asia Pacific Region, prevalence of allergic rhinitis varied from 13.1 to $39.7 \%$. The highest prevalence was noted in Taiwan (39.8\%), China (27.6\%), Japan (15\%) and Thailand (13.1\%). ${ }^{89}$

Allergic rhinitis (AR) is common among the Thai population and is diagnosed in approximately $40 \%$ of children and $26 \%$ of adolescents. ${ }^{90}$ Allergic rhinitis and asthma share a common inflammatory response, including mediators, cytokines, and chemokines released from mast cells and basophils. ${ }^{91} \mathrm{Up}$ to $70 \%$ of asthmatics suffer from rhinitis, and significant correlations between asthma and rhinitis severities have been found. ${ }^{2}$

Clinical studies have shown that the pharmacologic treatment of rhinitis is capable of improving the outcomes of asthma and vice versa. However, systemic treatment approaches such as specific immunotherapy and type- 2 biologic agents lead to improved outcomes for asthma and allergic rhinitis.

Treatment with second-generation $\mathrm{H} 1$-antihistamines, typically used for controlling classic symptoms of AR, may also have a beneficial effect on asthma symptoms. ${ }^{87}$ Intranasal corticosteroid treatment has been shown to significantly reduce asthma symptoms and reliever usage. ${ }^{94}$

Sublingual immunotherapy (SLIT) in asthma patients with concomitant AR has been shown to reduce asthma symptoms and exacerbation when the patient's dosage of inhaled corticosteroids has been reduced. ${ }^{95}$

\section{Gastroesophageal reflux disease and asthma}

Gastroesophageal reflux disease (GERD) occurs when acid refluxes into the esophagus from the stomach. Previous studies have demonstrated a connection between nocturnal GERD and asthma. Asthma prevalence was higher and nocturnal asthma symptoms were more common in nocturnal GERD patients compared to those with non-nocturnal GERD. ${ }^{96}$ However, screening all uncontrolled asthma patients for GERD is not currently recommended. The underlying physiology involves microaspiration associated with vagally mediated esophagobronchial reflex. Current evidence supports empirical GERD treatment in asthmatic patients with symptomatic GERD. Further investigation, such as 24-h $\mathrm{pH}$ monitoring, may be later considered if reflux symptoms do not resolve after treatment. Treatment options include anti-reflux medications such as proton pump inhibitors and motility agents. Previous studies have found improvement in PEFR, $\mathrm{FEV}_{1}$, reflux symptom score, daytime asthma symptoms score, and night time asthmatic score with these treatments. ${ }^{97-100}$ Some studies have found that GERD treatment improved daytime and nighttime asthma symptom scores - but not pulmonary function - in asthmatic patients with GERD. ${ }^{101}$ On the other hand, other studies have shown improvement in parametric pulmonary function but not daytime or night time symptom scores. ${ }^{98}$ 


\section{Obesity and asthma}

Asthma is prevalent in the overweight and obese population. ${ }^{102}$ One previous study found $37 \%$ of severe asthmatic patients to be obese. ${ }^{103}$ Underlying pathophysiology and mechanistic pathways include increased systemic inflammation involving leptin, IL-5, IL-13, IL-17, chemokine C-C motif ligand (CCL17), C-reactive protein (CRP), and interferon (IFN)- $\gamma$; metabolic dysregulation associated with increased systemic inflammation; increased adipose tissue related to the adiponectin effect, and issues involving the microbiome. ${ }^{104-107}$ A pulmonary function test will usually reveal a reduction in forced vital capacity (FVC) and forced expiratory volume in 1 second $\left(\mathrm{FEV}_{1}\right)$ without significant difference in $\mathrm{FEV}_{1} / \mathrm{FVC}{ }^{103}$ Reductions in expiratory reserve volume (ERV) and functional residual capacity (FRC) are also frequently observed, the former of which is linearly correlated with BMI. ${ }^{108}$ Being overweight or obese may also affect the small airway due to smooth muscle dysfunction associated with airway hyperresponsiveness. ${ }^{109}$ Obesity itself also increases the risk of obstructive sleep apnea (OSA) and GERD. Weight reduction is strongly recommended in asthma patients with obesity as a comorbidity. A previous study found that 5-10\% weight reduction in these patients can improve asthma control, quality of life, and pulmonary function. ${ }^{110}$ Standard asthma therapy, including inhaled corticosteroids, is the cornerstone treatment for asthma in obese patients. However, a previous study demonstrated that treatment response may be lower in overweight/obese asthmatic patients. ${ }^{111}$

\section{Obstructive sleep apnea and asthma}

OSA is characterized by repetitive upper airway obstruction during sleep associated with intermittent oxygen desaturation and/or arousal. Many studies have shown OSA and asthma to be affected by underlying physiology including nerve reflex stimulation, intermittent hypoxia, vascular endothelial growth factors, and leptin-mediated pathways. ${ }^{112}$ Previous studies showed a higher prevalence of OSA in asthmatic patients compared to healthy controls, particularly in patients with uncontrolled asthma, indicating an association between OSA and asthma control. ${ }^{113,114}$ Studies have also found a higher prevalence of asthma in OSA patients compared to that observed in the normal population. ${ }^{115}$ The first-line treatment for OSA is continuous positive airway pressure (CPAP). There is evidence supporting the use of CPAP in asthmatic patients with coexisting OSA, as it may reduce days of asthma, nocturnal asthma attacks, and nighttime symptom scores, as well as improve ACT score, mean PEFR, $\% \mathrm{FEV}_{1}$, and quality of life. ${ }^{112}$

\section{Depression and anxiety disorders and asthma}

If asthmatic patients suffer from psychological disorders, these disorders may be exacerbated by insufficient control of asthma symptoms. Studies have found a higher rate of depression in severe asthmatic patients than in the general population. Clinicians should thus observe asthma patients for symptoms/family history of psychological problems and refer patients with possible mental disorders to a psychiatrist for diagnosis and treatment. ${ }^{116}$

\section{Treatment of asthma in special conditions Exercise-induced bronchoconstriction}

Exercise may aggravate asthma symptoms, which may occur within a few minutes after finishing exercise. There are various techniques to reduce exercise-induced bronchoconstriction including pre-exercise warm-up and SABA or formoterol-budesonide inhalation. Good asthma control through regular ICS use may also improve this condition. ${ }^{117}$

\section{Asthma in pregnancy}

In pregnant women, asthma is equally likely to worsen, stabilize, or improve. Asthma can be used both postpartum and during pregnancy, as uncontrolled asthma during pregnancy carries a greater risk than the side effects from medications. As lowering medication dosage may cause acute asthma exacerbation, it is generally recommended that the patient's normal dosage be maintained during pregnancy. In cases of acute asthma exacerbation, standard treatment regimens are justified. During the delivery period, regional anesthesia is preferable to general anesthesia if anesthesia is needed. ${ }^{118}$

\section{Aspirin-exacerbated respiratory disease (AERD)}

AERD, also known as NSAID-exacerbated respiratory disease (NERD), is an inflammatory respiratory disease with three dominant characters: chronic sinusitis with nasal polyps, asthma, and hypersensitivity to aspirin or non-selective cyclooxygenase (COX) inhibitor non-steroidal anti-inflammatory drugs (NSAIDs). ${ }^{119}$ The mechanisms of this disease are unknown. It is postulated that AERD may be associated with abnormal metabolism of arachidonic acid, resulting in lower prostaglandin E2 and increases in leukotriene E4 and cysteinyl leukotriene. This induces white blood cell (particularly eosinophil) migration to both the upper and lower airway. This phenomenon may result in airway inflammation and can occur at any time, even absent aspirin or NSAIDs. ${ }^{120}$ Symptoms of airway hyperresponsiveness after aspirin or non-selective COX inhibitor NSAID administration include nasal congestion, runny nose, dyspnea, and asthma attack. ${ }^{121,122}$ The prevalence of AERD is higher in patients with severe asthma than in the overall asthmatic population (14\% vs $7 \%) .{ }^{123}$ Patients may also have anosmia, recurrent episodes of sinusitis, and asthma exacerbation despite treatment with medications or sinus/ nasal polyp surgery. ${ }^{124}$ In summary, AERD patients tend to have more severe, unresponsive airway inflammation than the general asthmatic population despite standard treatment. Diagnosis of AERD is based on compatible history and physical examination. An oral, bronchial, or intranasal aspirin challenge test can be performed for confirmation of the condition. ${ }^{120}$

Treatment of AERD consists of avoidance of aspirin or non-selective COX inhibitor NSAIDs. AERD patients can safely use selective COX-2 inhibitor NSAIDs or acetaminophen $(500 \mathrm{mg}) .{ }^{120,125}$ Treatment of asthma in AERD patients consists of inhaled corticosteroids and other standard asthma treatments. Antileukotriene can be used as an additional treatment, as it has been shown to reduce symptoms and improve quality of life. ${ }^{126,127}$ Intranasal steroids are recommended 
as in treatment of sinusitis. Sinus and nasal polyp surgery can be performed if indicated. However, nasal polyps may reoccur soon after the surgery. In such cases or in patients whose asthma remains uncontrolled despite standard treatment, referral to a specialist for aspirin desensitization or biologic treatment is recommended.

Aspirin desensitization is performed by administering aspirin in gradually increasing doses up to $325 \mathrm{mg}$ under the care of specialists, after which $325-650 \mathrm{mg}$ of aspirin is administered twice daily on a continuous basis. ${ }^{120}$ High doses of aspirin may cause gastrointestinal side effects such as abdominal pain or upper gastrointestinal bleeding. Some studies have found that $300 \mathrm{mg} /$ day of aspirin can be effective in controlling of symptoms with few gastrointestinal side effects. ${ }^{128,129}$ The mechanisms of aspirin desensitization in controlling AERD are unknown but may be related to decreases in leukotriene E4. ${ }^{122}$

Currently, biologic treatment for asthma or sinusitis with nasal polyps with favorable outcomes in AERD patients include anti-IgE (omalizumab), anti-IL5 (mepolizumab, reslizumab), anti-IL5 receptor (benralizumab), and anti-IL 4 receptor a (dupilumab). ${ }^{130,131}$ However, biologic medications are expensive and target-based and should thus be used cautiously with consideration of indications and clinical characteristics specific to the individual patient.

\section{Asthma and surgery}

Prior to surgery, asthma patients should be evaluated for asthma control and to determine the appropriate type of anesthesia and surgical procedure. Patients' best FEV ${ }_{1}$ should be $80 \%$ or over. General anesthesia with intubation and surgery on the airway, thorax, or abdomen carries a risk of airway constriction. ${ }^{132}$

Smoking cessation should occur at least two months prior to surgery, and the patient should exhibit normal pulmonary function. If pulmonary function is lower than normal, administration of $1 \mathrm{mg} / \mathrm{kg} /$ day of oral prednisolone (maximum of $40 \mathrm{mg}$ ) for 5 days prior to surgery should be considered. If the preoperative period is less than 5 days, intravenous corticosteroids with a short-acting inhaled bronchodilator can be substituted. ${ }^{133}$ For patients previously treated with high-dose corticosteroids for a long duration or oral corticosteroids for more than 2 weeks in the past 6 months, intravenous hydrocortisone should be given to reduce the risk of adrenal crisis. ${ }^{134}$

\section{Severe and uncontrolled asthma}

Severe asthma is different from uncontrolled asthma. Severe asthma is asthma that is difficult to control even with high-dose medications and control of risk factors. Despite treatment, asthma symptoms are still frequent and severe. ${ }^{7,135}$ Uncontrolled asthma, however, is defined by symptoms that are unable to be controlled by medication or severe symptoms with triggers such as exercise, allergens, or upper respiratory tract infection. Uncontrolled asthma patients may have frequent nocturnal symptoms, or acute exacerbation more than twice per year and may require unscheduled visits or oral corticosteroids multiple times per year due to dyspnea.
Such patients are considered to have severe, uncontrolled asthma. Note that uncontrolled asthma may be mild and that only a small portion of severe patients have uncontrolled asthma. The percentage of asthma patients with severe and uncontrolled asthma is $3.7 \%$ and $17 \%$, respectively. ${ }^{136}$

\section{Importance of severe asthma}

Severe asthma results in frequent dyspnea and leads to disturbance of daily life, sleep, work, and school. Additionally, severe patients may require frequent use of oral corticosteroids, which cause long-term side effects and complications such as obesity, diabetes, osteoporosis, cataract, hypertension, depression, and suppression of the pituitary-adrenal axis. ${ }^{137,138}$ Severe asthma also affects various other aspects of a patient's life including family, social life, work, and vacation/leisure time. Severe asthma may also cause a heavy economic burden due to both the direct and indirect cost of care. Patients may incur direct costs due to medication, hospital visits (some of which may be unscheduled, requiring additional medical personnel), and treatment of long-term side effects from medications (such as oral corticosteroids), as well as indirect costs due to the patient or their caregivers needing to be absent from work.

\section{Diagnosis of severe asthma}

Severe, uncontrolled asthma is defined by presence of severe asthma at all times and/or frequent asthma attacks despite receiving step-4 and step-5 treatment based on GINA guidelines. ${ }^{137}$ Asthma symptoms in these patients are still severe, even after having been treated with inhaled corticosteroids at moderate or high doses with a combination of long-acting bronchodilators and other oral medications. ${ }^{139}$ This condition is caused by the asthma itself and not patient non-compliance.

\section{Differential diagnoses}

There are several conditions that mimic asthma including chronic obstructive pulmonary disease (COPD), obesity, heart disease, insufficient exercise, laryngeal diseases causing chronic cough, upper respiratory tract disease, gastroesophageal reflux disease (GERD), and antihypertensive medications. ${ }^{87,140-145}$ COPD is the most common disease that may be mistaken for severe asthma as it causes wheezing. Other conditions that cause wheezing include laryngeal diseases or upper airway obstruction. ${ }^{146}$

\section{Situations in which the patient should referred to a specialist for severe asthma ${ }^{147}$}

- Inability diagnose or differentially diagnose the condition

- Frequent emergency room visits

- Frequent or regular oral corticosteroid use

- Suspected occupational asthma

- Suspected severe food allergy or anaphylaxis

- Suspected heart disease or infection

- Suspected COPD

- Symptoms of or suspected comorbid disease causing difficulty in diagnosis 
Laboratory investigations for diagnosis and differential diagnosis of severe asthma ${ }^{147}$

Spirometry is a crucial laboratory test as it shows pulmonary function before and after bronchodilator use and can detect airway constriction. If asthma symptoms are present but the first pulmonary function test does not show bronchodilator reversibility (increase in $\mathrm{FEV}_{1}<200 \mathrm{~mL}$ or $<12 \%$ from the baseline prebronchodilator level), repeat spirometry should be performed. A flow-volume curve is also needed to evaluate upper airway obstruction.

If spirometry is not feasible, a home peak flow meter should be used to identify variability. Bronchial provocation testing should be considered if the above tests are all normal but severe asthma is still suspected.

Additionally, in asthma patients with clinical features of chronic respiratory obstruction, it may be worthwhile to perform a pulmonary function test at baseline and subsequent follow-up visits to evaluate severity. Referral to a specialist is justified if the diagnosis is uncertain or spirometry is not possible.

\section{Common causes of severe asthma}

1. Incorrect inhaler technique

2. Non- or poor compliance

3. Comorbid diseases that cause dyspnea such as obesity, depression, upper respiratory airway diseases, laryngeal diseases, gastoesophageal reflux disease (GERD), chronic obstructive pulmonary disease (COPD), cardiac diseases, or spinal diseases

4. Risk factors for uncontrolled asthma such as poor environmental conditions, smoking, allergens in the home or workplace, or use of medications associated with asthma, i.e., beta blockers or nonsteroidal anti-inflammatory drugs (NSAIDs) including aspirin. ${ }^{148}$

5. Ineffective response to short-acting of bronchodilators. ${ }^{149}$ Use of more than 3 canister/year of short-acting $\beta 2$-agonits as bronchodilator relivers may be an indicator for acute severe asthma and is associated with risk for exacerbation requiring an emergency room visit or hospital admission. ${ }^{150,151}$

6. Psychological problems or socioeconomic status associated with undertreatment substandard treatment. ${ }^{152}$

7. Medications, particularly oral corticosteroids, causing long term side effects and/or poor patient compliance.

\section{Evaluation and appropriate treatment}

Patients with severe asthma should be evaluated to determine whether they are receiving appropriate treatment, their treatments are specific to their individual needs, they have treatment plans in place if their symptoms improve or become more severe, and they have learned how to use their inhalers correctly. Physicians should also recheck patients' inhaler technique regularly during the outpatient visits and attempt to determine causes of non-compliance. ICS-formoterol maintenance and relievers may be appropriate if the patient has frequent asthma attacks, as they may prevent severe asthma attack $^{153}$ and the dosage can be adjusted by the patient. ${ }^{30,32} \mathrm{Co}-$ morbid diseases associated with asthma, such as allergic rhinitis or sinusitis, should also be treated. Steps should be taken if the physician observes avoidance of medications associated with asthma exacerbation, and evidence of depression or other psychological symptoms should be managed by referral to a specialist.

Non-pharmacological treatments should be considered at each visit including smoking cessation, exercise, healthy diet, weight reduction, influenza vaccination, and avoidance of allergens. Additional medications such as tiotropium bromide (soft mist inhaler), leukotriene modifiers, high-dose inhaled corticosteroids administered according to asthma guidelines may be justified if severe asthma persists after all environmental causes are eliminated. ${ }^{147}$

\section{Follow-up at 3-6 months}

During follow-up visits, physicians should evaluate asthma severity, inhaler device technique, medication side effects, pulmonary function, and patient satisfaction. If the patient still has severe asthma after correcting possible environmental factors, biologics may be justified. Which biologics are appropriate depends on the patient's clinical features or asthma phenotype.

\section{Asthma phenotypes}

The type- 2 asthma phenotype is associated with good response to several medications (e.g., corticosteroids). ${ }^{154-157}$ However, there is limited evidence regarding the effectiveness of non-type 2 treatments, including biologics, in type- 2 low asthma patients. Other factors need to be considered prior to biologic treatment including comorbid diseases, psychosocial status, and availability of biologics. Biologic agents tend to be more accessible in clinical research facilities than in other settings, and there is more clinical data regarding their use in severe asthma in such facilities.

\section{Type-2 Asthma Phenotype}

The majority of severe asthma patients have been found to have the type-2 phenotype. Clinical features of this phenotype are presence of allergy, young asthma onset, non-obesity, presence of eosinophils in blood of 150 cells/ $\mu \mathrm{L}$ or over and in sputum of $2 \%$ or over, and FeNO of 20 ppb or over. ${ }^{7}$ The epithelial origin cytokines or alarmins include IL-25, IL-33, and thymic stromal lymphopoietin (TSLP) are responsible to allergens, viral, and bacterial infection. These cytokines are associated with activation of innate lymphoid cell type- 2 and $\mathrm{T}$ helper-2 lymphocytes in patients with type- 2 asthma phenotype. $^{158}$

The indication for type 2 biologics for severe asthma have been addressed. Firstly, omalizumab as anti-IgE is indicated in patients with allergic asthma by evidence of allergen sensitization with high serum IgE. In addition, omalizumab is also indicated in chronic spontaneous urticaria. Furthermore, anti-IL5 (mepolizumab and reslizumab) and anti-IL5R (benralizumab) are indicated in severe eosinophilic asthma with high blood eosinophilia and history of asthma exacerbation. Lastly, anti-IL4R (dupilumab) is indicated in corticosteroid dependent asthma with high blood eosinophilia or high FeNO. Meanwhile, omalizumab, benralizumab and dupilumab was approved for being added on asthma treatment in Thailand. 
Table 5. Registered and available biologics for severe asthma.

\begin{tabular}{|c|c|c|c|c|c|c|}
\hline Generic name & Brand name & Action & Administration & $\begin{array}{l}\text { Frequency } \\
\text { (weeks) }\end{array}$ & $\begin{array}{l}\text { Patient age } \\
\text { (years) }\end{array}$ & Side effects \\
\hline Omalizumab & Xolair & Anti-IgE & SC & $2-4$ & 6 & Pain at injection site, anaphylaxis (few) \\
\hline Mepolizumab & Nucala & Anti-IL5 & SC & 4 & 12 & Pain at injection site \\
\hline Reslizumab & Cinqair & Anti-IL5 & IV & 4 & 6 & Pain at the injection site \\
\hline Benralizumab & Fasenra & Anti-IL5R & SC & $4-8$ & 12 & Pain at injection site \\
\hline Dupilumab & Dupixent & Anti-IL4R & SC & 2 & 12 & $\begin{array}{l}\text { Pain at the injection site, red eyes, } \\
\text { increase blood eosinophils }\end{array}$ \\
\hline Tezepelumab & NA in Thailand & Anti-TSLP & SC & $2-4$ & NA & Pain at the injection site \\
\hline
\end{tabular}

Abbreviations: SC (subcutaneous), IV (intravenous), Anti-IL5 (anti-interleukin 5), Anti-IL5R (anti-interleukin 5 receptor), Anti-IL4R (anti-interleukin 4 receptor), NA: not available

Patients with the type-2 asthma phenotype can be treated with the biologics, as show in Table $4 .^{154-157,159-162}$

For patients with the non-type- 2 phenotype, non-pharmacological treatment, such as bronchial thermoplasty, should be given. ${ }^{163}$

\section{Follow-up in severe asthma}

Standard follow-up examinations for asthma, medication administration, and medication side effects should be performed every 1-3 months in patients with severe asthma.

Severe, uncontrolled asthma is defined as asthma that remains uncontrolled even after step-4 and step-5 treatment according to the GINA strategy and control for risk factors and occurrence of asthma attack when stepping down therapy. Prevalence of severe, uncontrolled asthma is $3-10 \%$ in asthma patients. Severe asthma has physical, psychosocial, and economic impacts on patients. Treatment of these patients should be performed with great care. First, the diagnosis of asthma should be definite. Then, risk factors for severe asthma should be evaluated. Quality of life should also be considered, as well as prevention of future severe asthma. Referral to a specialist should be considered if symptoms remain uncontrolled, i.e., if symptoms continue or the patient experiences frequent asthma attacks despite high-dose inhaled corticosteroid treatment. Differential diagnoses should performed. Asthma phenotype may be a crucial factor in determining whether to administer medication in addition to inhaled corticosteroids. Choices for additional treatment include tiotropium bromide, leukotrienes receptor antagonist, or biologic agents. Oral corticosteroids should be avoided due to the possibility of long-term side effects. The clinical efficacy of additional medications should be evaluated in patients with severe asthma, as well as their clinical status after withdrawal of medications. Alternative treatments should be considered at every visit. A multidisciplinary team is needed for these patients, and referral to specialists is warranted in selected cases. Clinical research facilities and severe asthma patient groups may facilitate better clinical treatment of severe asthma.

\section{Thai Alternative Medicine in Asthma}

Complementary and alternative medicine (CAM), such as acupuncture and herbal medicine, is popular in many regions. There is some evidence to support the use of acupuncture as an alternative therapy for asthma. However, the mechanisms underlying its effects are not fully understood. The WHO listed asthma as an indication for acupuncture and the National Institutes of Health have since recommended acupuncture as an adjunctive treatment for asthma. ${ }^{164}$ Traditional herbal medicine is widely used in Asia (including Thailand). Zingiber cassumunar Roxb. (known as phlai in Thai) has been used as a traditional medicine in Thailand for treatment of asthma and allergy-related diseases. Previous studies have shown that the bioactive components of phlai exhibit anti-inflammatory, smooth muscle relaxant, antihistamine, and mucin-lowering secretion properties. ${ }^{165-169}$ Phlai also inhibits 5-lipoxygenase enzyme and is a cysteinyl leukotriene receptor antagonist. ${ }^{170} \mathrm{~A}$ preliminary study on the effect of treatment with Phlai capsules on bronchial hyperresponsiveness in asthmatic patients found that it tended to decrease BHR and significantly improved symptom scores without side effects. ${ }^{170}$

\section{Asthma and coronavirus disease-19 (COVID-19)}

The outbreak of the novel coronavirus in 2019 has increased morbidities and mortalities globally. Primary infection is of the respiratory tracts and may cause pneumonia and respiratory failure leading to fatality. ${ }^{171,172}$ Epidemiological studies have shown that asthma and respiratory allergies are uncommon underlying diseases in COVID-19 patients, ${ }^{162-164}$ despite viral infection being a common cause of asthma exacerbation. ${ }^{173-175}$ However, increased susceptibility to COVID-19 is related to higher expression of angiotensin-2 (ACE-2) receptors in the respiratory system, and a previous study found ACE-2 expression in airway epithelium obtained from patients with asthma compared to healthy subjects. The use of inhaled corticosteroids reduces ACE-2 receptor expression in asthma in a dose-dependent manner. ${ }^{176}$ Since the expression levels of ACE2 and TMPRSS2 gene were similar in asthma and healthy subjects. There was no subgroup analysis regarding allergic and non-allergic asthma phenotypes. 
However, respiratory allergies, allergen exposures, high IgE and allergen sensitization were associated with a decrease in ACE2 expression in the nasal and bronchial epithelium of asthma patients. In addition, low ACE2 expression was not associated with non-atopic asthma. Hence, the reduced ACE2 expression is protective factors in patients with respiratory allergies for reduced COVID-19 severity. ${ }^{177}$

Thus, although there is no conclusive evidence that asthma patients are at greater risk of COVID-19, patients should be assiduous in continuing their regular controller treatments, including inhaled corticosteroids, long-term oral corticosteroids, and biologics, during the COVID-19 pandemic.

The management of asthma exacerbation during the COVID-19 pandemic is challenging. Asthma may be exacerbated as a result of respiratory viral or bacterial infection. The common viral causes of exacerbation are rhinovirus, human coronavirus, and adenovirus. ${ }^{178,179}$ Nebulization is key to bronchodilator drug delivery in acute respiratory emergency (e.g., asthma and COPD exacerbation). However, as SARSCoV2 spreads through droplets containing the virus produced by coughing and sneezing, concerns have been raised regarding the possibility of airborne spread of viral particles during nebulization and aerosol-generating procedures (AGPs). ${ }^{180-183}$ Hence, some asthma guidelines recommend refraining from nebulization both in patients with and those without clinically suspected COVID-19. ${ }^{184-187}$ Instead a metered-dose inhaler (MDI) with spacer, which exhibits similar efficacy to nebulization, should be used according to these recommendations. ${ }^{188}$ However, the risk of aerosol spread of viruses from nebulization is debated, and other asthma guidelines state that nebulization does not spread viral droplets. ${ }^{28,189-194}$ Currently, the risk of SARS-CoV-2 infection among healthcare providers from nebulization and aerosol-generating procedures (AGPs) has only been extrapolated from previous epidemiological studies of severe acute respiratory syndrome (SARS) and has not yet been examined systematically. ${ }^{195}$ However, high-risk patients who are critically ill, elderly and disabled patients who cannot use MDI, or patients who do not cooperate with treatment may require specific methods of drug delivery during exacerbation. The role of systemic corticosteroids in severe COVID-19 has not been established. However, in patients with asthma exacerbation, systemic corticosteroids are necessary whether or not there is clinical suspicion of COVID-19. ${ }^{196}$

\section{The perspectives of guidelines for the manage- ment of asthma in adults: Evidence and Recom- mendations by Thai Asthma Council (TAC)}

Asthma is a common respiratory disease in Thailand. However, the burden of uncontrolled asthma in Thailand is high and associated with increased healthcare cost utilization. Thai Asthma Council (TAC) asthma recommendation emphasizes holistic care for asthma including confirmation of the diagnosis, setting asthma management goals, initiating an asthma management process, and determining a treatment plan, as shown in Figure 1-5.
The perspectives of this guideline and recommendation are conveniences and being practical in the context of health care limited resource setting and primary healthcare sectors. The recommendation focusing on the regular use of ICS in mild asthma who are less symptomatic and escalation level of asthma medications together with integrative approach for improving asthma outcomes. Apart from medications, the TAC guideline focuses on non-pharmacological therapies including patient education for maximizing asthma outcomes. Lastly, TAC asthma recommendation provides asthma management schema during COVID-19 pandemic in setting of stable asthma and asthma exacerbation. Again, herbal use in asthma and alternative medicine are progressively interesting issue for chronic medical diseases including asthma particularly in Thailand.

The difference of TAC recommendation from Global Initiative for asthma (GINA) is that the choice of initial controller and preferred reliever medications. The limitation of available asthma medication in Thailand is key issue and limitation for following the guideline. The TAC committee believed that despite of robust evidence and complexity of approach for diagnosis and asthma treatment. The simplicity and applicability of guideline are pivotal for implementation in Thailand. Meanwhile, the asthma control situation in Thailand is very poor include symptoms control and asthma exacerbation despite of the available ICS containing treatment of asthma. ${ }^{3}$

The asthma control in Asia Pacific region is unacceptably low. However, many countries in this region have shared the common the barriers for achieving the asthma treatment in terms of medication accessibility as well as the perception regarding clinicians and patients on asthma. The findings are similar other regions, current levels of asthma control in the Asia-Pacific region fall markedly short of goals specified in international guidelines for asthma management. The ICS users was low as $13.6 \%$. However, the reliance on rapid reliver bronchodilator was $56.3 \%$. Absence from school and work in the previous year was reported by $36.5 \%$ of children and $26.5 \%$ of adults in this region. ${ }^{197}$

Despite the epidemiological survey demonstrates a universal acceptance of coexistent asthma and allergic rhinitis. The high disease burden has been reported. It highlights the need for increased healthcare practitioner communication and awareness regarding the disease management. This is aimed to improve appropriate treatment and management of these coexistent conditions in this region. ${ }^{198}$

For these reasons, the local recommendations, and guidelines for improving management of asthma are needed in Asia Pacific region. According to the contexts of problems and barrier to overcome have been shared in several countries. The geographical similarities, the healthcare system, socioeconomic and cultural perspectives are also needed to address. 


\section{Acknowledgements}

Thai clinical practice guidelines for the diagnosis and management of asthma in adult patients were first issued in 1997. This is an updated version of those guidelines edited by multidisciplinary experts in Thailand and organized by the Thai Asthma Council (TAC)

The authors would like to thank Prof. Dr. Kittisak Sawanyawisuth, Khon Kaen University, Thailand for his kind assistance in manuscript preparation.

\section{References}

1. Dejsomritrutai W, Nana A, Chierakul N, Tscheikuna J, Sompradeekul S, Ruttanaumpawan P, et al. Prevalence of bronchial hyperresponsiveness and asthma in the adult population in Thailand. Chest. 2006;129(3):602-9.

2. Chantaphakul H, Luangdilok T, Ruxrungtham K, Klaewsongkram J. Inpatient asthma mortality in a tertiary referral hospital from 2000 to 2010. Asian Pac J Allergy Immunol. 2012;30(3):193-6.

3. Boonsawat W, Thompson PJ, Zaeoui U, Samosorn C, Acar G, Faruqi R, et al. Survey of asthma management in Thailand - the asthma insight and management study. Asian Pac J Allergy Immunol. 2015;33(1):14-20.

4. Boonpiyathad T, Yimsawad S, Sangasapaviriya A. The Cost of Asthma Treatment in Phramongkutlao Hospital: Population-Based Study in Adults. J Med Assoc Thail Chotmaihet Thangphaet. 2016;99(1):51-7.

5. Thompson PJ, Salvi S, Lin J, Cho YJ, Eng P, Abdul Manap R, et al. Insights, attitudes and perceptions about asthma and its treatment: findings from a multinational survey of patients from 8 Asia-Pacific countries and Hong Kong. Respirol Carlton Vic. 2013;18(6):957-67.

6. Boonsawat W, Charoenphan P, Kiatboonsri S, Wongtim S, Viriyachaiyo V, Pothirat C, et al. Survey of asthma control in Thailand. Respirol Carlton Vic. 2004;9(3):373-8.

7. Global Initial for Asthma. Global strategy for Asthma Management and Prevention, 2018 [Internet]. Fontana; Global Initial for Asthma; 2018 [cited 2021 Apr 4]. Available from: https://ginasthma.org/wp-content/ uploads/2019/01/2018-GINA.pdf

8. Worldwide variations in the prevalence of asthma symptoms: the International Study of Asthma and Allergies in Childhood (ISAAC). Eur Respir J. 1998;12(2):315-35.

9. Lee TH. Precipitating factors of asthma. Br Med Bull. 1992;48(1):169-78.

10. Hanania NA, Celli BR, Donohue JF, Martin UJ. Bronchodilator reversibility in COPD. Chest. 2011;140(4):1055-63.

11. Reddel HK. Peak flow monitoring in clinical practice and clinical asthma trials. Curr Opin Pulm Med. 2006;12(1):75-81.

12. Reddel HK, Salome CM, Peat JK, Woolcock AJ. Which index of peak expiratory flow is most useful in the management of stable asthma? Am J Respir Crit Care Med. 1995;151(5):1320-5.

13. Crapo RO, Casaburi R, Coates AL, Enright PL, Hankinson JL, Irvin CG, et al. Guidelines for methacholine and exercise challenge testing-1999. This official statement of the American Thoracic Society was adopted by the ATS Board of Directors, July 1999. Am J Respir Crit Care Med. 2000;161(1): 309-29.

14. National Asthma Education and Prevention Program. Expert Panel Report 3 (EPR-3): Guidelines for the Diagnosis and Management of Asthma-Summary Report 2007. J Allergy Clin Immunol. 2007;120(5 Suppl):S94-138.

15. Expert Panel Working Group of the National Heart, Lung, and Blood Institute (NHLBI) administered and coordinated National Asthma Education and Prevention Program Coordinating Committee (NAEPPCC), Cloutier MM, Baptist AP, Blake KV, Brooks EG, Bryant -Stephens T, et al. 2020 Focused Updates to the Asthma Management Guidelines: A Report from the National Asthma Education and Prevention Program Coordinating Committee Expert Panel Working Group. J Allergy Clin Immunol. 2020;146(6):1217-70.

16. British Thoracic Society, Scottish Intercollegiate Guidelines Network. British guideline on the management of asthma. Thorax. 2003;58 Suppl 1: i1-94.

17. Boulet LP, Bai TR, Becker A, Bérubé D, Beveridge R, Bowie DM, et al. What is new since the last (1999) Canadian Asthma Consensus Guidelines? Can Respir J. 2001;8 Suppl A:5A-27A.
18. Taylor DR, Bateman ED, Boulet L-P, Boushey HA, Busse WW, Casale TB, et al. A new perspective on concepts of asthma severity and control. Eur Respir J. 2008;32(3):545-54.

19. Juniper EF, Bousquet J, Abetz L, Bateman ED, GOAL Committee. Identifying "well-controlled" and "not well-controlled" asthma using the Asthma Control Questionnaire. Respir Med. 2006;100(4):616-21.

20. Nathan RA, Sorkness CA, Kosinski M, Schatz M, Li JT, Marcus P, et al. Development of the asthma control test: a survey for assessing asthma control. J Allergy Clin Immunol. 2004;113(1):59-65.

21. Schatz M, Sorkness CA, Li JT, Marcus P, Murray JJ, Nathan RA, et al. Asthma Control Test: reliability, validity, and responsiveness in patients not previously followed by asthma specialists. J Allergy Clin Immunol. 2006;117(3):549-56.

22. Bateman ED, Boushey HA, Bousquet J, Busse WW, Clark TJH, Pauwels RA, et al. Can guideline-defined asthma control be achieved? The Gaining Optimal Asthma ControL study. Am J Respir Crit Care Med. 2004;170(8): 836-44.

23. Bateman ED, Reddel HK, Eriksson G, Peterson S, Ostlund O, Sears MR, et al. Overall asthma control: the relationship between current control and future risk. J Allergy Clin Immunol. 2010;125(3):600-8, 608.e1-608.e6.

24. Kharitonov S, Alving K, Barnes PJ. Exhaled and nasal nitric oxide measurements: recommendations. The European Respiratory Society Task Force. Eur Respir J. 1997;10(7):1683-93.

25. Djukanović R, Sterk PJ, Fahy JV, Hargreave FE. Standardised methodology of sputum induction and processing. Eur Respir J Suppl. 2002;37:1s-2s.

26. Kawamatawong T, Siripongpun S, Rerkpattanapipat T. Role of eosinophilic inflammation and atopy in elderly asthmatic patients. Asia Pac Allergy. 2016;6(3):181-6.

27. Rau JL. The inhalation of drugs: advantages and problems. Respir Care. 2005;50(3):367-82.

28. Cazzola M, Page CP, Calzetta L, Matera MG. Pharmacology and therapeutics of bronchodilators. Pharmacol Rev. 2012;64(3):450-504.

29. Boulet LP, Cowie RL, Negro RD, Brett W, Gold M, Marques A, et al. Comparison of once- with twice-daily dosing of fluticasone propionate in mild and moderate asthma. Can Respir J. 2000;7(3):239-47.

30. Bateman ED, Reddel HK, O'Byrne PM, Barnes PJ, Zhong N, Keen C, et al. As-Needed Budesonide-Formoterol versus Maintenance Budesonide in Mild Asthma. N Engl J Med. 2018;378(20):1877-87.

31. Pauwels RA, Pedersen S, Busse WW, Tan WC, Chen Y-Z, Ohlsson SV, et al. Early intervention with budesonide in mild persistent asthma: a randomised, double-blind trial. Lancet Lond Engl. 2003;361(9363):1071-6.

32. O’Byrne PM, FitzGerald JM, Bateman ED, Barnes PJ, Zhong N, Keen C, et al. Inhaled Combined Budesonide-Formoterol as Needed in Mild Asthma. N Engl J Med. 2018;378(20):1865-76.

33. Beasley R, Holliday M, Reddel HK, Braithwaite I, Ebmeier S, Hancox RJ, et al. Controlled Trial of Budesonide-Formoterol as Needed for Mild Asthma. N Engl J Med. 2019;380(21):2020-30.

34. Hardy J, Baggott C, Fingleton J, Reddel HK, Hancox RJ, Harwood $\mathrm{M}$, et al. Budesonide-formoterol reliever therapy versus maintenance budesonide plus terbutaline reliever therapy in adults with mild to moderate asthma (PRACTICAL): a 52-week, open-label, multicentre, superiority, randomised controlled trial. Lancet Lond Engl. 2019; 394(10202):919-28.

35. Bernstein DI, Hébert J, Cheema A, Murphy KR, Chérrez-Ojeda I, Matiz-Bueno CE, et al. Efficacy and onset of action of mometasone furoate/formoterol and fluticasone propionate/salmeterol combination treatment in subjects with persistent asthma. Allergy Asthma Clin Immunol. 2011;7:21.

36. Boonsawat W, Thinkhamrop B. Role of budesonide/formoterol maintenance and reliever therapy: a pragmatic study. Asian Pac J Allergy Immunol. 2014;32(2):160-5.

37. Pauwels RA, Löfdahl CG, Postma DS, Tattersfield AE, O’Byrne P, Barnes PJ, et al. Effect of inhaled formoterol and budesonide on exacerbations of asthma. Formoterol and Corticosteroids Establishing Therapy (FACET) International Study Group. N Engl J Med. 1997;337(20):1405-11.

38. Kaplan A, Ryan D. The role of budesonide/formoterol for maintenance and relief in the management of asthma. Pulm Pharmacol Ther. 2010; 23(2):88-96.

39. Papi A. Inhaled BDP/formoterol extra-fine combination. Evidence and future perspectives. Pneumol Stuttg Ger. 2009;63 Suppl 2:S102-106. 
40. Papi A, Corradi M, Pigeon-Francisco C, Baronio R, Siergiejko Z, Petruzzelli S, et al. Beclometasone-formoterol as maintenance and reliever treatment in patients with asthma: a double-blind, randomised controlled trial. Lancet Respir Med. 2013;1(1):23-31.

41. Polosa R, Thomson NC. Smoking and asthma: dangerous liaisons. Eur Respir J. 2013;41(3):716-26.

42. Osei AD, Mirbolouk M, Orimoloye OA, Dzaye O, Uddin SMI, Dardari $\mathrm{ZA}$, et al. The association between e-cigarette use and asthma among never combustible cigarette smokers: behavioral risk factor surveillance system (BRFSS) 2016 \& 2017. BMC Pulm Med. 2019;19(1):180.

43. Perret JL, Bonevski B, McDonald CF, Abramson MJ. Smoking cessation strategies for patients with asthma: improving patient outcomes. J Asthma Allergy. 2016;9:117-28.

44. Vieira RP, Claudino RC, Duarte ACS, Santos ABG, Perini A, Faria Neto HCC, et al. Aerobic exercise decreases chronic allergic lung inflammation and airway remodeling in mice. Am J Respir Crit Care Med. 2007;176(9):871-7.

45. Mendes FAR, Gonçalves RC, Nunes MPT, Saraiva-Romanholo BM, Cukier A, Stelmach R, et al. Effects of aerobic training on psychosocial morbidity and symptoms in patients with asthma: a randomized clinical trial. Chest. 2010;138(2):331-7.

46. Jaakkola JJK, Aalto SAM, Hernberg S, Kiihamäki S-P, Jaakkola MS. Regular exercise improves asthma control in adults: A randomized controlled trial. Sci Rep. 2019;9(1):12088.

47. Thomas M, Bruton A. Breathing exercises for asthma. Breathe. 2014; 10(4):312.

48. Santino TA, Chaves GS, Freitas DA, Fregonezi GA, Mendonça KM. Breathing exercises for adults with asthma. Cochrane Database Syst Rev. 2020;3:CD001277.

49. de Groene GJ, Pal TM, Beach J, Tarlo SM, Spreeuwers D, Frings-Dresen $\mathrm{MH}$, et al. Workplace interventions for treatment of occupational asthma. Cochrane Database Syst Rev. 2011;(5):CD006308.

50. Salpeter S, Ormiston T, Salpeter E. Cardioselective beta-blockers for reversible airway disease. Cochrane Database Syst Rev. 2002;(4):CD002992.

51. Wilson JM, Platts-Mills TAE. Home Environmental Interventions for House Dust Mite. J Allergy Clin Immunol Pract. 2018;6(1):1-7.

52. Ma J, Strub P, Xiao L, Lavori PW, Camargo CA, Wilson SR, et al. Behavioral weight loss and physical activity intervention in obese adults with asthma. A randomized trial. Ann Am Thorac Soc. 2015;12(1):1-11.

53. Sheikh A. Evidence-based problem solving: What is the efficacy of pneumococcal vaccination in people with asthma? Prim Care Respir J. 1999;7(2):21-2.

54. Sheikh A, Alves B, Dhami S. Pneumococcal vaccine for asthma. Cochrane Database Syst Rev. 2002;(1):CD002165.

55. Castro M, Rubin AS, Laviolette M, Fiterman J, De Andrade Lima M, Shah PL, et al. Effectiveness and safety of bronchial thermoplasty in the treatment of severe asthma: a multicenter, randomized, double-blind, sham-controlled clinical trial. Am J Respir Crit Care Med. 2010;181(2): $116-24$.

56. Wechsler ME, Laviolette M, Rubin AS, Fiterman J, Lapa e Silva JR, Shah PL, et al. Bronchial thermoplasty: Long-term safety and effectiveness in patients with severe persistent asthma. J Allergy Clin Immunol. 2013; 132(6):1295-302.

57. Chupp G, Laviolette M, Cohn L, McEvoy C, Bansal S, Shifren A, et al. Long-term outcomes of bronchial thermoplasty in subjects with severe asthma: a comparison of 3-year follow-up results from two prospective multicentre studies. Eur Respir J. 2017;50(2):1700017.

58. Sun Q, Fang L, Roth M, Tang X, Papakonstantinou E, Zhai W, et al. Bronchial thermoplasty decreases airway remodelling by blocking epithelium-derived heat shock protein-60 secretion and protein arginine methyltransferase-1 in fibroblasts. Eur Respir J. 2019;54(6):1900300.

59. Thanthitaweewat V, Leelayuwatanakul N, Sriprasart T. Bronchial thermoplasty in Thailand: 3-year experience in real-world practice. Eur Respir J. 2020;56(suppl 64):2621.

60. Gibson PG, Powell H, Coughlan J, Wilson AJ, Abramson M, Haywood $\mathrm{P}$, et al. Self-management education and regular practitioner review for adults with asthma. Cochrane Database Syst Rev. 2003;(1):CD001117.

61. Mishra R, Kashif M, Venkatram S, George T, Luo K, Diaz-Fuentes G. Role of Adult Asthma Education in Improving Asthma Control and Reducing Emergency Room Utilization and Hospital Admissions in an Inner City Hospital. Can Respir J. 2017;2017:5681962.
62. Hirunyanitiwattana T, Pirompanich $\mathrm{P}$, Boonya-anuchit $\mathrm{P}$, Maitree $\mathrm{T}$, Poachanukoon O. Effectiveness of Asthma Knowledge in Nurses using Asthma Care Application Compared with Written Asthma Action Plan. J Med Assoc Thai. 2020;103(4):16.

63. Lakupoch K, Manuyakorn W, Preutthipan A, Kamalaporn H. The effectiveness of newly developed written asthma action plan in improvement of asthma outcome in children. Asian Pac J Allergy Immunol. 2018;36(2):88-92.

64. Dekhuijzen PNR, Vincken W, Virchow JC, Roche N, Agusti A, Lavorini F, et al. Prescription of inhalers in asthma and COPD: towards a rational, rapid and effective approach. Respir Med. 2013;107(12):1817-21.

65. Kawamatawong T, Khiawwan S, Pornsuriyasak P. Peak inspiratory flow rate measurement by using In-Check DIAL for the different inhaler devices in elderly with obstructive airway diseases. J Asthma Allergy. 2017;10:17-21.

66. Sirimontakan T, Manuyakorn W, Kamalaporn H, Wattanarungsun $P$, Chonpaisan K, Thongkum K, et al. Efficacy of a newly developed cartoon video on dry powder inhaler technique: a multicenter study. Asian Pac J Allergy Immunol. 2019 in press.

67. Chien JW, Ciufo R, Novak R, Skowronski M, Nelson J, Coreno A, et al Uncontrolled oxygen administration and respiratory failure in acute asthma. Chest. 2000;117(3):728-33.

68. Rodrigo GJ, Rodriquez Verde M, Peregalli V, Rodrigo C. Effects of short-term $28 \%$ and $100 \%$ oxygen on $\mathrm{PaCO} 2$ and peak expiratory flow rate in acute asthma: a randomized trial. Chest. 2003;124(4):1312-7.

69. Perrin K, Wijesinghe M, Healy B, Wadsworth K, Bowditch R, Bibby S, et al. Randomised controlled trial of high concentration versus titrated oxygen therapy in severe exacerbations of asthma. Thorax. 2011;66(11):937-41.

70. Cates CJ, Welsh EJ, Rowe BH. Holding chambers (spacers) versus nebulisers for beta-agonist treatment of acute asthma. Cochrane Database Syst Rev. 2013;(9):CD000052.

71. Turner MO, Patel A, Ginsburg S, FitzGerald JM. Bronchodilator delivery in acute airflow obstruction. A meta-analysis. Arch Intern Med. 1997;157(15):1736-44.

72. Rodrigo GJ, Castro-Rodriguez JA. Anticholinergics in the treatment of children and adults with acute asthma: a systematic review with meta-analysis. Thorax. 2005;60(9):740-6.

73. Lanes SF, Garrett JE, Wentworth CE, Fitzgerald JM, Karpel JP. The effect of adding ipratropium bromide to salbutamol in the treatment of acute asthma: a pooled analysis of three trials. Chest. 1998;114(2):365-72.

74. Hasegawa T, Ishihara K, Takakura S, Fujii H, Nishimura T, Okazaki M, et al. Duration of systemic corticosteroids in the treatment of asthma exacerbation; a randomized study. Intern Med Tokyo Jpn. 2000;39(10): 794-7.

75. Jones AM, Munavvar M, Vail A, Aldridge RE, Hopkinson L, Rayner C, et al. Prospective, placebo-controlled trial of 5 vs 10 days of oral prednisolone in acute adult asthma. Respir Med. 2002;96(11):950-4.

76. Alangari AA. Corticosteroids in the treatment of acute asthma. Ann Thorac Med. 2014;9(4):187-92.

77. Fiel SB, Swartz MA, Glanz K, Francis ME. Efficacy of short-term corticosteroid therapy in outpatient treatment of acute bronchial asthma. Am J Med. 1983;75(2):259-62.

78. Rodrigo GJ. Rapid effects of inhaled corticosteroids in acute asthma: an evidence-based evaluation. Chest. 2006;130(5):1301-11.

79. Edmonds ML, Milan SJ, Camargo CA, Pollack CV, Rowe BH. Early use of inhaled corticosteroids in the emergency department treatment of acute asthma. Cochrane Database Syst Rev. 2012;12:CD002308.

80. Nowak RM, Pensler MI, Sarkar DD, Anderson JA, Kvale PA, Ortiz AE, et al. Comparison of peak expiratory flow and FEV1 admission criteria for acute bronchial asthma. Ann Emerg Med. 1982;11(2):64-9.

81. Weber EJ, Silverman RA, Callaham ML, Pollack CV, Woodruff PG, Clark $\mathrm{S}$, et al. A prospective multicenter study of factors associated with hospital admission among adults with acute asthma. Am J Med. 2002;113(5):371-8.

82. Kew KM, Kirtchuk L, Michell CI. Intravenous magnesium sulfate for treating adults with acute asthma in the emergency department. Cochrane Database Syst Rev. 2014;(5):CD010909.

83. Goodacre S, Cohen J, Bradburn M, Stevens J, Gray A, Benger J, et al The $3 \mathrm{Mg}$ trial: a randomised controlled trial of intravenous or nebulised magnesium sulphate versus placebo in adults with acute severe asthma. Health Technol Assess Winch Engl. 2014;18(22):1-168.

84. Parameswaran K, Belda J, Rowe BH. Addition of intravenous aminophylline to beta2-agonists in adults with acute asthma. Cochrane Database Syst Rev. 2000;(4):CD002742. 
85. Lim WJ, Mohammed Akram R, Carson KV, Mysore S, Labiszewski NA, Wedzicha JA, et al. Non-invasive positive pressure ventilation for treatment of respiratory failure due to severe acute exacerbations of asthma. Cochrane Database Syst Rev. 2012;12:CD004360.

86. Rosati MG, Peters AT. Relationships among allergic rhinitis, asthma, and chronic rhinosinusitis. Am J Rhinol Allergy. 2016;30(1):44-7.

87. Giavina-Bianchi P, Aun MV, Takejima P, Kalil J, Agondi RC. United airway disease: current perspectives. J Asthma Allergy. 2016;9:93-100.

88. Bousquet J, Khaltaev N, Cruz AA, Denburg J, Fokkens WJ, Togias A, et al. Allergic Rhinitis and its Impact on Asthma (ARIA) 2008 update (in collaboration with the World Health Organization, GA(2)LEN and AllerGen). Allergy. 2008;63 Suppl 86:8-160.

89. Ozdoganoglu T, Songu M. The burden of allergic rhinitis and asthma. Ther Adv Respir Dis. 2012;6(1):11-23.

90. Phankingthongkum S, Daengsuwan T, Visitsunthorn N, Thamlikitkul V, Udompunthuruk S, Vichyanond P. How do Thai children and adolescents describe asthma symptoms? Pediatr Allergy Immunol. 2002;13(2):119-24.

91. Bachert C, Maspero J. Efficacy of second-generation antihistamines in patients with allergic rhinitis and comorbid asthma. J Asthma Off J Assoc Care Asthma. 2011;48(9):965-73.

92. Pothirat C, Phetsuk N, Liwsrisakun C, Bumroongkit C, Deesomchok A, Theerakittikul T. Major Chronic Respiratory Diseases in Chiang Mai: Prevalence, Clinical Characteristics, and Their Correlations. J Med Assoc Thai. 2016;99(9):1005-13.

93. Lohia S, Schlosser RJ, Soler ZM. Impact of intranasal corticosteroids on asthma outcomes in allergic rhinitis: a meta-analysis. Allergy. 2013;68(5): 569-79.

94. Zielen S, Devillier P, Heinrich J, Richter H, Wahn U. Sublingual immunotherapy provides long-term relief in allergic rhinitis and reduces the risk of asthma: A retrospective, real-world database analysis. Allergy. 2018;73(1):165-77.

95. Gislason T, Janson C, Vermeire P, Plaschke P, Björnsson E, Gislason D, et al. Respiratory symptoms and nocturnal gastroesophageal reflux: a population-based study of young adults in three European countries. Chest. 2002;121(1):158-63.

96. Goodall RJ, Earis JE, Cooper DN, Bernstein A, Temple JG. Relationship between asthma and gastro-oesophageal reflux. Thorax. 1981;36(2):116-21.

97. Kiljander TO, Harding SM, Field SK, Stein MR, Nelson HS, Ekelund J, et al. Effects of esomeprazole $40 \mathrm{mg}$ twice daily on asthma: a randomized placebo-controlled trial. Am J Respir Crit Care Med. 2006;173(10):1091-7.

98. Sharma B, Sharma M, Daga MK, Sachdev GK, Bondi E. Effect of omeprazole and domperidone on adult asthmatics with gastroesophageal reflux. World J Gastroenterol. 2007;13(11):1706-10.

99. Sandur V, Murugesh M, Banait V, Rathi PM, Bhatia SJ, Joshi JM, et al. Prevalence of gastro-esophageal reflux disease in patients with difficult to control asthma and effect of proton pump inhibitor therapy on asthma symptoms, reflux symptoms, pulmonary function and requirement for asthma medications. J Postgrad Med. 2014;60(3):282-6.

100. Kiljander TO, Salomaa ER, Hietanen EK, Terho EO. Gastroesophageal reflux in asthmatics: A double-blind, placebo-controlled crossover study with omeprazole. Chest. 1999;116(5):1257-64.

101. Akinbami LJ, Fryar CD. Current Asthma Prevalence by Weight Status Among Adults: United States, 2001-2014. NCHS Data Brief. 2016;(239): $1-8$.

102. Moore WC, Meyers DA, Wenzel SE, Teague WG, Li H, Li X, et al. Identification of asthma phenotypes using cluster analysis in the Severe Asthma Research Program. Am J Respir Crit Care Med. 2010;181(4): 315-23.

103. Zhang X, Zheng J, Zhang L, Liu Y, Chen GP, Zhang HP, et al. Systemic inflammation mediates the detrimental effects of obesity on asthma control. Allergy Asthma Proc. 2018;39(1):43-50.

104. Rastogi D, Fraser S, Oh J, Huber AM, Schulman Y, Bhagtani RH, et al. Inflammation, metabolic dysregulation, and pulmonary function among obese urban adolescents with asthma. Am J Respir Crit Care Med. 2015;191(2):149-60.

105. Bianco A, Nigro E, Monaco ML, Matera MG, Scudiero O, Mazzarella G, et al. The burden of obesity in asthma and COPD: Role of adiponectin. Pulm Pharmacol Ther. 2017;43:20-5.

106. Peters U, Dixon AE, Forno E. Obesity and asthma. J Allergy Clin Immunol. 2018;141(4):1169-79.

107. Sin DD, Sutherland ER. Obesity and the lung: 4. Obesity and asthma. Thorax. 2008;63(11):1018-23.
108. Litonjua AA, Sparrow D, Celedon JC, DeMolles D, Weiss ST. Association of body mass index with the development of methacholine airway hyperresponsiveness in men: the Normative Aging Study. Thorax. 2002;57(7):581-5.

109. Scott HA, Gibson PG, Garg ML, Pretto JJ, Morgan PJ, Callister R, et al. Dietary restriction and exercise improve airway inflammation and clinical outcomes in overweight and obese asthma: a randomized trial. Clin Exp Allergy. 2013;43(1):36-49.

110. Telenga ED, Tideman SW, Kerstjens H a. M, Hacken NHTT, Timens W, Postma DS, et al. Obesity in asthma: more neutrophilic inflammation as a possible explanation for a reduced treatment response. Allergy. 2012;67(8):1060-8.

111. Julien JY, Martin JG, Ernst P, Olivenstein R, Hamid Q, Lemière C, et al. Prevalence of obstructive sleep apnea-hypopnea in severe versus moderate asthma. J Allergy Clin Immunol. 2009;124(2):371-6.

112. Abdul Razak MR, Chirakalwasan N. Obstructive sleep apnea and asthma. Asian Pac J Allergy Immunol. 2016;34(4):265-71.

113. Guven SF, Dursun AB, Ciftci B, Erkekol FO, Kurt OK. The prevalence of obstructive sleep apnea in patients with difficult-to-treat asthma. Asian Pac J Allergy Immunol. 2014;32(2):153-9.

114. Alharbi M, Almutairi A, Alotaibi D, Alotaibi A, Shaikh S, Bahammam AS. The prevalence of asthma in patients with obstructive sleep apnoea. Prim Care Respir J J Gen Pract Airw Group. 2009;18(4):328-30.

115. Opolski M, Wilson I. Asthma and depression: a pragmatic review of the literature and recommendations for future research. Clin Pract Epidemiol Ment Health CP EMH. 2005 27;1:18.

116. Lazarinis N, Jørgensen L, Ekström T, Bjermer L, Dahlén B, Pullerits T, et al. Combination of budesonide/formoterol on demand improves asthma control by reducing exercise-induced bronchoconstriction. Thorax. 2014; 69(2):130-6.

117. Gluck JC, Gluck PA. Asthma controller therapy during pregnancy. Am J Obstet Gynecol. 2005;192(2):369-80.

118. Kowalski ML, Agache I, Bavbek S, Bakirtas A, Blanca M, Bochenek G, et al. Diagnosis and management of NSAID-Exacerbated Respiratory Disease (N-ERD)-a EAACI position paper. Allergy. 2019;74(1):28-39.

119. White AA, Stevenson DD. Aspirin-Exacerbated Respiratory Disease. N Engl J Med. 2018;379(11):1060-70.

120. Szczeklik A, Nizankowska E. Clinical features and diagnosis of aspirin induced asthma. Thorax. 2000;55 Suppl 2:S42-44.

121. Szczeklik A, Nizankowska E, Duplaga M. Natural history of aspirin -induced asthma. AIANE Investigators. European Network on Aspirin -Induced Asthma. Eur Respir J. 2000;16(3):432-6.

122. Rajan JP, Wineinger NE, Stevenson DD, White AA. Prevalence of aspirin -exacerbated respiratory disease among asthmatic patients: A meta-analysis of the literature. J Allergy Clin Immunol. 2015;135(3):676-681.e1.

123. Berges-Gimeno MP, Simon RA, Stevenson DD. The natural history and clinical characteristics of aspirin-exacerbated respiratory disease. Ann Allergy Asthma Immunol. 2002;89(5):474-8.

124. Settipane RA, Schrank PJ, Simon RA, Mathison DA, Christiansen SC, Stevenson DD. Prevalence of cross-sensitivity with acetaminophen in aspirin-sensitive asthmatic subjects. J Allergy Clin Immunol. 1995;96(4): $480-5$.

125. Dahlén B, Nizankowska E, Szczeklik A, Zetterström O, Bochenek G, Kumlin M, et al. Benefits from adding the 5-lipoxygenase inhibitor zileuton to conventional therapy in aspirin-intolerant asthmatics. Am J Respir Crit Care Med. 1998;157(4 Pt 1):1187-94.

126. Dahlén S-E, Malmström K, Nizankowska E, Dahlén B, Kuna $P$, Kowalski $\mathrm{M}$, et al. Improvement of aspirin-intolerant asthma by montelukast, a leukotriene antagonist: a randomized, double-blind, placebo-controlled trial. Am J Respir Crit Care Med. 2002;165(1):9-14.

127. Comert S, Celebioglu E, Yucel T, Erdogan T, Karakaya G, Onerci M, et al. Aspirin $300 \mathrm{mg} /$ day is effective for treating aspirin-exacerbated respiratory disease. Allergy. 2013;68(11):1443-51.

128. Wongsa C, Sompornrattanaphan M, Tantilipikorn P, Thongngarm T Clinical characteristics and aspirin desensitization in Thai patients with a suggestive history of NSAID-exacerbated respiratory disease. Asian Pac J Allergy Immunol. 2019 in press.

129. White AA, Woessner K, Simon R. Aspirin-exacerbated respiratory disease: Update on medical management. World J Otorhinolaryngol - Head Neck Surg. 2020;6(4):241-7.

130. Laidlaw TM, Mullol J, Fan C, Zhang D, Amin N, Khan A, et al. Dupilumab improves nasal polyp burden and asthma control in patients with CRSwNP and AERD. J Allergy Clin Immunol Pract. 2019;7(7):2462-2465.e1. 
131. Woods BD, Sladen RN. Perioperative considerations for the patient with asthma and bronchospasm. Br J Anaesth. 2009;103 Suppl 1:i57-65.

132. Silvanus M-T, Groeben H, Peters J. Corticosteroids and inhaled salbutamol in patients with reversible airway obstruction markedly decrease the incidence of bronchospasm after tracheal intubation. Anesthesiology. 2004;100(5):1052-7.

133. Wakim JH, Sledge KC. Anesthetic implications for patients receiving exogenous corticosteroids. AANA J. 2006;74(2):133-9.

134. Chung KF, Wenzel SE, Brozek JL, Bush A, Castro M, Sterk PJ, et al. International ERS/ATS guidelines on definition, evaluation and treatment of severe asthma. Eur Respir J. 2014;43(2):343-73.

135. Hekking P-PW, Wener RR, Amelink M, Zwinderman AH, Bouvy ML, Bel $\mathrm{EH}$. The prevalence of severe refractory asthma. J Allergy Clin Immunol. 2015;135(4):896-902.

136. Lefebvre P, Duh MS, Lafeuille M-H, Gozalo L, Desai U, Robitaille M-N, et al. Acute and chronic systemic corticosteroid-related complications in patients with severe asthma. J Allergy Clin Immunol. 2015;136(6):1488-95.

137. Waljee AK, Rogers MAM, Lin P, Singal AG, Stein JD, Marks RM, et al. Short term use of oral corticosteroids and related harms among adults in the United States: population based cohort study. BMJ. 2017;357:j1415.

138. Chantaphakul H, Ruxrungtham K. Fixed-Dose combination of the inhaled corticosteroid and long-acting beta2-agonist therapy in adults with persistent asthma. Expert Opin Pharmacother. 2016;17(5):631-42.

139. Sawunyavisuth B. What are predictors for a continuous positive airway pressure machine purchasing in obstructive sleep apnea patients? Asia-Pac J Sci Technol. 2018;23(3):APST-23-03-10.

140. Wangsan K, Chaiear N, Sawanyawisuth K, Klainin P, Simajareuk K. Pattern of shiftwork and health status among nurses in a university hospital in northeastern Thailand. Asia-Pac J Sci Technol. 2019;24(2): APST-24-02-08.

144. Rittidet C, Chaiear N, Tumsatan P, Domthong P, Sukkasem W, Burge PS. Proportion of occupational progressive fibrosing interstitial lung disease in the tertiary hospitals of Thailand. Asia-Pac J Sci Technol. 2021;26(04): APST-26-04-07

145. Chantaphakul H, Rock MJ, Steiner DS, Gern JE. Mediastinal fibrosis presenting as asthma. Allergy Asthma Proc. 1998;19(3):125-9.

146. Global Initial for Asthma. Global strategy for Asthma Management and Prevention, 2019 [Internet]. Fontana; Global Initial for Asthma; 2019 [cited 2021 Apr 4]. Available from: https://ginasthma.org/wp-content/ uploads/2019/06/GINA-2019-main-report-June-2019-wms.pdf

147. Supakthanasiri P, Klaewsongkram J, Chantaphakul H. Reactivity of allergy skin test in healthy volunteers. Singapore Med J. 2014;55(1):34-6.

148. Hancox RJ, Cowan JO, Flannery EM, Herbison GP, McLachlan CR, Taylor DR. Bronchodilator tolerance and rebound bronchoconstriction during regular inhaled beta-agonist treatment. Respir Med. 2000;94(8):767-71.

149. Stanford RH, Shah MB, D'Souza AO, Dhamane AD, Schatz M. Short-acting $\beta$-agonist use and its ability to predict future asthma-related outcomes. Ann Allergy Asthma Immunol. 2012;109(6):403-7.

150. Suissa S, Ernst P, Benayoun S, Baltzan M, Cai B. Low-dose inhaled corticosteroids and the prevention of death from asthma. N Engl J Med. 2000;343(5):332-6.

151. Foster JM, McDonald VM, Guo M, Reddel HK. "I have lost in every facet of my life": the hidden burden of severe asthma. Eur Respir J. 2017;50(3):1700765.

152. Sobieraj DM, Weeda ER, Nguyen E, Coleman CI, White CM, Lazarus SC, et al. Association of Inhaled Corticosteroids and Long-Acting $\beta$-Agonists as Controller and Quick Relief Therapy With Exacerbations and Symptom Control in Persistent Asthma: A Systematic Review and Meta-analysis. JAMA. 2018;319(14):1485-96.

153. Busse WW. Biological treatments for severe asthma: where do we stand? Curr Opin Allergy Clin Immunol. 2018;18(6):509-18.

154. Busse W, Chupp G, Nagase H, Albers FC, Doyle S, Shen Q, et al. Anti-IL-5 treatments in patients with severe asthma by blood eosinophil thresholds: Indirect treatment comparison. J Allergy Clin Immunol. 2019;143(1): 190-200.e20.

155. Busse WW, Bleecker ER, FitzGerald JM, Ferguson GT, Barker P, Sproule S, et al. Long-term safety and efficacy of benralizumab in patients with severe, uncontrolled asthma: 1-year results from the BORA phase 3 extension trial. Lancet Respir Med. 2019;7(1):46-59.

156. Castro M, Corren J, Pavord ID, Maspero J, Wenzel S, Rabe KF, et al. Dupilumab Efficacy and Safety in Moderate-to-Severe Uncontrolled Asthma. N Engl J Med. 2018;378(26):2486-96.

157. Israel E, Reddel HK. Severe and Difficult-to-Treat Asthma in Adults. N Engl J Med. 2017;377(10):965-76.
158. Peters SP, Busse WW. New and Anticipated Therapies for Severe Asthma. J Allergy Clin Immunol Pract. 2017;5(5S):S15-24.

159. Rabe KF, Nair P, Brusselle G, Maspero JF, Castro M, Sher L, et al. Efficacy and Safety of Dupilumab in Glucocorticoid-Dependent Severe Asthma. N Engl J Med. 2018;378(26):2475-85.

160. Corren J, Parnes JR, Wang L, Mo M, Roseti SL, Griffiths JM, et al Tezepelumab in Adults with Uncontrolled Asthma. N Engl J Med. 2017; 377(10):936-46.

161. Kawamatawong T, Poachanukoon O, Boonsiri C, Saengasapaviriya A, Saengasapaviriya A, Sittipunt C, et al. Long-term effectiveness of omalizumab treatment in Thai severe asthmatic patients: A real-life experience. Asian Pac J Allergy Immunol. 2018;36(4):238-43.

162. Langton D, Sloan G, Banks C, Bennetts K, Plummer V, Thien F. Bronchial thermoplasty increases airway volume measured by functional respiratory imaging. Respir Res. 2019;20(1):157.

163. Wang W-Q, Xu Y-D, Cui L-P, Yin L-M, Wang Y, Liu Y-Y, et al. Acupuncture has a positive effect on asthmatic rats in a glucocorticoid -independent manner. Acupunct Med J Br Med Acupunct Soc. 2016; 34(6):433-40.

164. Panthong A, Kanjanapothi D, Niwatananant W, Tuntiwachwuttikul P, Reutrakul V. Anti-inflammatory activity of compound D \{(E)-4-(3',4' -dimethoxyphenyl)but-3-en-2-ol $\}$ isolated from Zingiber cassumunar Roxb. Phytomedicine Int J Phytother Phytopharm. 1997;4(3):207-12.

165. Tewtrakul S, Subhadhirasakul S. Anti-allergic activity of some selected plants in the Zingiberaceae family. J Ethnopharmacol. 2007;109(3):535-8.

166. Kanjanapothi D, Soparat P, Panthong A, Tuntiwachwuttikul P, Reutrakul V. A uterine relaxant compound from Zingiber cassumunar. Planta Med. 1987;53(4):329-32.

167. Tanticharoenwiwat P, Kulalert P, Dechatiwongse Na Ayudhya T, Koontongkaew S, Jiratchariyakul W, Soawakontha R, et al. Inhibitory effect of Phlai capsules on skin test responses among allergic rhinitis patients: a randomized, three-way crossover study. J Integr Med. 2017;15(6):462-8.

168. Limvuttegrijerat T, Poachanukoon O, Koontongkaew S, Na Ayudhya TD Crude ethanolic extracts of Zingiber cassumunar ROXB. inhibit PMA -induced MUC2 and MUC5AC expression via ERK inhibition in human airway epithelial cells. Asian Pac J Allergy Immunol. 2014;32(4):328-36.

169. Dulpinijthamma J, Poachanukoon O, Saiphoklang N. The effect of Zingiber cassumunar (Phlai capsule) on bronchial hyperresponsiveness in asthmatic patients. J Allergy Clin Immunol. 2020;145(2):AB20.

170. Harapan H, Itoh N, Yufika A, Winardi W, Keam S, Te H, et al. Coronavirus disease 2019 (COVID-19): A literature review. J Infect Public Health. 2020;13(5):667-73.

171.Zhang J-J, Dong X, Cao Y-Y, Yuan Y-D, Yang Y-B, Yan Y-Q, et al. Clinical characteristics of 140 patients infected with SARS-CoV-2 in Wuhan, China. Allergy. 2020;75(7):1730-41.

172. CDC COVID-19 Response Team. Preliminary Estimates of the Prevalence of Selected Underlying Health Conditions Among Patients with Coronavirus Disease 2019 - United States, February 12-March 28, 2020. MMWR Morb Mortal Wkly Rep. 2020;69(13):382-6.

173. Richardson S, Hirsch JS, Narasimhan M, Crawford JM, McGinn T, Davidson KW, et al. Presenting Characteristics, Comorbidities, and Outcomes Among 5700 Patients Hospitalized With COVID-19 in the New York City Area. JAMA. 2020;323(20):2052-9.

174. Bhatraju PK, Ghassemieh BJ, Nichols M, Kim R, Jerome KR, Nalla AK, et al. Covid-19 in Critically Ill Patients in the Seattle Region - Case Series. N Engl J Med. 2020;382(21):2012-22.

175. Peters MC, Sajuthi S, Deford P, Christenson S, Rios CL, Montgomery MT, et al. COVID-19-related Genes in Sputum Cells in Asthma. Relationship to Demographic Features and Corticosteroids. Am J Respir Crit Care Med. 2020;202(1):83-90.

176. Jackson DJ, Busse WW, Bacharier LB, Kattan M, O’Connor GT, Wood RA, et al. Association of respiratory allergy, asthma, and expression of the SARS-CoV-2 receptor ACE2. J Allergy Clin Immunol. 2020;146(1): 203-206.e3.

177. Edwards MR, Bartlett NW, Hussell T, Openshaw P, Johnston SL. The microbiology of asthma. Nat Rev Microbiol. 2012;10(7):459-71.

178. Message SD, Johnston SL. The immunology of virus infection in asthma. Eur Respir J. 2001;18(6):1013-25.

179. Wilson NM, Norton A, Young FP, Collins DW. Airborne transmission of severe acute respiratory syndrome coronavirus- 2 to healthcare workers: a narrative review. Anaesthesia. 2020;75(8):1086-95.

180. van Doremalen N, Bushmaker T, Morris DH, Holbrook MG, Gamble A, Williamson BN, et al. Aerosol and Surface Stability of SARS-CoV-2 as Compared with SARS-CoV-1. N Engl J Med. 2020;382(16):1564-7. 
181. Chee VWT, Khoo ML-C, Lee SF, Lai YC, Chin NM. Infection control measures for operative procedures in severe acute respiratory syndrome -related patients. Anesthesiology. 2004;100(6):1394-8.

182. Howard BE. High-Risk Aerosol-Generating Procedures in COVID-19: Respiratory Protective Equipment Considerations. Otolaryngol--Head Neck Surg Off J Am Acad Otolaryngol-Head Neck Surg. 2020;163(1): 98-103.

183. Managing asthma during the COVID-19 (SARS-CoV-2) pandemic, 2021 [Internet]. South Melbourne; Australian Asthma Handbook; 2021 [cited 2021 Apr 4]. Available from: https://www.asthmahandbook.org.au/clinical -issues/covid-19

184. Licskai C, Yang CL, Ducharme FM, Radhakrishnan D, Podgers D, Ramsey C, et al. Key Highlights From the Canadian Thoracic Society Position Statement on the Optimization of Asthma Management During the Coronavirus Disease 2019 Pandemic. Chest. 2020;158(4):1335-7.

185. Amirav I, Newhouse MT. Transmission of coronavirus by nebulizer: a serious, underappreciated risk. CMAJ Can Med Assoc J J Assoc Medicale Can. 2020;192(13):E346.

186. Nebulizer use during the COVID-19 Pandemic, 2021 [Internet]. Arlington Heights; American College of Allergy, Asthma and Immunology; 2021 [cited $2021 \mathrm{Apr}$ 4]. Available from: https://college.acaai. org/nebulizer-use-during-the-covid-19-pandemic/

187. Wan G-H, Tsai Y-H, Wu Y-K, Tsao K-C. A large-volume nebulizer would not be an infectious source for severe acute respiratory syndrome. Infect Control Hosp Epidemiol. 2004;25(12):1113-5.

188. Sethi S, Barjaktarevic IZ, Tashkin DP. The use of nebulized pharmacotherapies during the COVID-19 pandemic. Ther Adv Respir Dis. 2020;14:1753466620954366.
189. Ari A. Practical strategies for a safe and effective delivery of aerosolized medications to patients with COVID-19. Respir Med. 2020;167:105987.

190. Hess MW. Nebulized Therapy in the COVID-19 Era: The Right Tool for the Right Patient [Letter]. Int J Chron Obstruct Pulmon Dis. 2020;15:2101-2.

191. Fink JB, Ehrmann S, Li J, Dailey P, McKiernan P, Darquenne C, et al. Reducing Aerosol-Related Risk of Transmission in the Era of COVID-19: An Interim Guidance Endorsed by the International Society of Aerosols in Medicine. J Aerosol Med Pulm Drug Deliv. 2020;33(6):300-4.

192. COVID-19 rapid guideline: severe asthma, 2021 [Internet]. London; National Institute for Health and Care Excellence; 2021 [cited 2021 Apr 4]. Available from: https://www.nice.org.uk/guidance/ng166

193. COVID-19: information for the respiratory community, 2021 [Internet]. London; British Thoracic Society; 2021 [cited 2021 Apr 4]. Available from: https://www.brit-thoracic.org.uk/covid-19/covid-19-information-for -the-respiratory-community/

194. Tran K, Cimon K, Severn M, Pessoa-Silva CL, Conly J. Aerosol generating procedures and risk of transmission of acute respiratory infections to healthcare workers: a systematic review. PloS One. 2012;7(4):e35797.

195. Kumar K, Hinks TSC, Singanayagam A. Treatment of COVID-19 -exacerbated asthma: should systemic corticosteroids be used? Am J Physiol Lung Cell Mol Physiol. 2020;318(6):L1244-7.

196. Lai CKW, De Guia TS, Kim Y-Y, Kuo S-H, Mukhopadhyay A, Soriano JB, et al. Asthma control in the Asia-Pacific region: the Asthma Insights and Reality in Asia-Pacific Study. J Allergy Clin Immunol. 2003;111(2):263-8.

197. Aggarwal B, Shantakumar S, Hinds D, Mulgirigama A. Asia-Pacific Survey of Physicians on Asthma and Allergic Rhinitis (ASPAIR): physician beliefs and practices about diagnosis, assessment, and treatment of coexistent disease. J Asthma Allergy. 2018;11:293-307. 